\title{
Frontline employees' collaboration in industrial service innovation: routes of co-creation's effects on new service performance
}

\author{
María Leticia Santos-Vijande $^{1}$ - José Ángel López-Sánchez ${ }^{2} \cdot$ John Rudd $^{3}$
}

Received: 7 July 2014 / Accepted: 22 April 2015 / Published online: 24 May 2015

(C) Academy of Marketing Science 2015

\begin{abstract}
From a Service-Dominant Logic (S-DL) perspective, employees constitute operant resources that firms can draw to enhance the outcomes of innovation efforts. While research acknowledges that frontline employees (FLEs) constitute, through service encounters, a key interface for the transfer of valuable external knowledge into the firm, the range of potential benefits derived from FLE-driven innovation deserves more investigation. Using a sample of knowledge intensive business services firms (KIBS), this study examines how the collaboration with FLEs along the new service development (NSD) process, namely FLE co-creation, impacts on service innovation performance following two routes of different effects. Partial least squares structural equation modeling (PLSSEM) results indicate that FLE co-creation benefits the NS success among FLEs and firm's customers, the constituents of the resources route. FLE co-creation also has a positive effect on the NSD speed, which in turn enhances the NS quality. NSD speed and NS quality integrate the operational route, which proves to be the most effective path to impact the NS market performance. Accordingly, KIBS managers must
\end{abstract}

María Leticia Santos-Vijande

1santos@uniovi.es

José Ángel López-Sánchez

jangel@unex.es

John Rudd

j.m.rudd@aston.ac.uk

1 Facultad de Economía y Empresa, Universidad de Oviedo, Avda. del Cristo s/n, 33071 Oviedo, Asturias, Spain

2 Facultad de Ciencias Económicas y Empresariales, Universidad de Extremadura, Avda. de Elvas s/n, 06071 Badajoz, Extremadura, Spain

3 Aston Business School, Aston University, Aston Triangle, Birmingham B4 7ET, UK value their FLEs as essential partners to achieve successful innovation from an internal and external perspective, and develop the appropriate mechanisms to guarantee their effective involvement along the NSD process.

Keywords Frontline employees $\cdot$ Knowledge intensive business services $\cdot$ New service co-creation $\cdot$ New service development speed $\cdot$ New service performance $\cdot$ New service quality

\section{Introduction}

Both scholars and management practitioners acknowledge that service innovation is of fundamental importance for the future competitive strength and growth of modern economies, as the service industry has gradually increased its contribution to the output and employment of developed countries (Cadwallader et al. 2010; Kuester et al. 2013; OECD 2012a, b). However, service innovation efforts often fail and, hence, do not achieve anticipated market and financial objectives (Cadwallader et al. 2010; Ottenbacher et al. 2006).

In response to this, an increasing body of research has focused on drivers of new service (NS) success, ${ }^{1}$ although empirical insights, when compared to the plethora of research available on product innovation, are relatively limited

\footnotetext{
$\overline{{ }^{1} \text { From a broad }}$ perspective, service innovation involves the creation of new or improved service offerings, service processes and service business models. In this study, the terms service innovation and new service are used without distinction meaning "an offering not previously available to a firm's customers resulting from the addition of a service offering or changes in the service concept that allow for the service offering to be made available" (Menor et al. 2002, p. 138).
} 
(Kuester et al. 2013; Lages and Piercy 2012). Nevertheless, from the evidence available, the new service development process (NSDP) is cited as a key controllable factor for firms that can contribute significantly to service innovation success (Kuester et al. 2013); therefore, implementation of the NSDP has become of critical interest to service innovation researchers (Alam 2002, 2006, 2012; Johne and Storey 1998; Storey and Hull 2010).

In this respect, recent studies explore the potential benefits for service innovation success that derive from the collaboration of different actors in the NSDP, such as customers, employees, or commercial partners (Alam 2002, 2012; Kesting and Ulhøi 2010; Melton and Hartline 2010, 2013; Ordanini and Parasuraman 2011). The role of frontline employees (FLEs), or those employees in direct contact with the firm's customers, has been the object of special attention. Through service encounters, FLEs are in an optimal position to collect information about customers' preferences (Engen and Magnusson 2015; Ye et al. 2012), and thereby they constitute a key interface for the transfer of valuable external knowledge into the NSDP (Atuahene-Gima 1996; Østergaarda et al. 2011). Thus, the literature provides several examples of firms that have taken advantage of FLEs' potential to generate successful service innovation ideas, for example, Singapore Airlines, Starbucks, Wal-Mart, and Tata Global Beverages in customer service markets (Lages and Piercy 2012), or Accenture Limited, BT Global Services (Smith and Mindrum 2008), HCL Technologies (Ramdas and Gajulapalli 2008), and RiteSolutions (Hoyt and Rao 2006) in business services markets. Moreover, other studies, such as Melton and Hartline (2013) and Ordanini and Parasuraman (2011), also illustrate the impact on NS success of a more in-depth collaboration with FLEs during the NSDP.

However, research on this topic remains scarce and is sometimes equivocal (Ordanini and Parasuraman 2011), as "some recent empirical work has contradicted conceptual roles assigned to FLEs by earlier researchers" (Melton and Hartline 2013, p. 69). Though some studies support the beneficial impact of FLEs' collaboration in the NSDP (Melton and Hartline 2010, 2013; Ordanini and Parasuraman 2011), others find little empirical support (Ottenbacher et al. 2006) or argue that it increases FLEs' workload and prevents FLEs from acting as catalysts for successful innovation (Johne and Storey 1998). This discussion is also extended by consideration of the potential shortcomings of employee-driven innovation (Kesting and Ulhøi 2010), and of the organizational conditions required for FLEs' successful participation in the NSDP (Cadwallader et al. 2010; Lages and Piercy 2012; Sørensen et al. 2013).

Nevertheless, the principles of Service-Dominant Logic (SDL) (Vargo and Lusch 2004, 2008) provide a conceptual framework for supporting the benefits of FLEs' engagement in the NSDP. According to S-DL, service innovation is based on the joint application of competences (i.e., knowledge and skills) by the firm and any other relevant actors (e.g., customers, employees, or business partners) (Lusch et al. 2007; Ordanini and Parasuraman 2011). Therefore, the knowledge and skills of FLEs transform them into valuable operant resources (resources capable of producing effects by acting on other resources) that firms can draw to enhance not only their innovation capability but also their service innovation performance (Edvardsson et al. 2012; Melton and Hartline 2010, 2013; Ordanini and Parasuraman 2011). Thus, FLEs' collaboration throughout the NSDP allows the transfer of FLEs' specific knowledge to the firm and supports the deployment of their skills, in this way becoming a significant key driver of the NS success.

In this context, innovation studies that apply an S-DL approach use the term innovation co-creation to refer to the participation of customers, employees, or business partners in the creation of the core offering (Hoyer et al. 2010; O'Hern and Rindfleisch 2010). In other words, the term innovation cocreation describes the engagement process undertaken in the "providers' sphere" (Grönroos and Voima 2013) to jointly design or co-produce (Lusch et al. 2007) the value proposition with customers, employees, and/or business partners. Accordingly, in our study, innovation co-creation is defined as a collaborative activity in the development of new products or new services in which one or more agents who are not directly linked to the firm's internal R\&D (such as customers, business partners, or employees) actively contribute to the process by providing and selecting different attributes of the new offer (Hoyer et al. 2010; O'Hern and Rindfleisch 2010). Likewise, the term FLE co-creation is used to refer to the FLEs' collaboration in the joint production process of an NS. Thus, FLE co-creation involves the joint work of FLEs with the firm's internal $\mathrm{R} \& \mathrm{D}$ /development team to integrate FLEs' knowledge and expertise into the NSDP, from the initial idea selection to the market launch of the NS. In this way, the research acknowledges that FLEs constitute a relevant knowledge interface for the organization, and that FLE co-creation constitutes a key knowledge transfer mechanism for supporting successful service innovation (Melton and Hartline 2013; Ordanini and Parasuraman 2011).

The main objective of this research, anchored in both the S$\mathrm{DL}$ and the service innovation literature, is to provide a more in-depth understanding of the benefits of FLE co-creation to NS success. To achieve this objective, we develop and test a theoretical model in a business service context that includes different NS performance criteria, as well as the relationships among these variables along two different routes of effects. In this way, our research offers four important contributions.

First, this study contributes to prior research that models FLEs as a key knowledge interface for service innovation success by examining the collaboration of FLEs throughout the entire NSDP, that is, from NS idea generation to market launch (Melton and Hartline 2010, 2013; Ordanini and 
Parasuraman 2011). Thus, using the S-DL framework, we consider FLEs to be valuable operant resources that provide useful knowledge and skills for defining a customer-centric service offering (Lusch et al. 2007). FLE co-creation, accordingly, is approached as an encompassing and integrative activity of FLEs' potential in the overall service innovation process. Our conceptualization of FLE co-creation as the comprehensive engagement of FLEs across all the NSDP stages expands the understanding of FLEs' role in service innovation.

Second, this study answers calls in the literature for more robust and comprehensive models for investigating the effects of employee-driven service innovation (Kesting and Ulhøi 2010; Melton and Hartline 2013; Menor et al. 2002). We examine, for the first time, the impact of FLE co-creation on internal and external service innovation performance measures (Hoyer et al. 2010; Umashankar et al. 2011). From an internal perspective, focusing on project work execution, our research explores the impact of FLE co-creation on NSD speed and NS quality, two key operational outcomes of the service innovation process (Atuahene-Gima 2003; Carbonell et al. 2009) that affect innovation success (McNally et al. 2011) and not previously considered in an FLE cocreation context. Also adopting an internal perspective, the investigation analyzes NS success among the FLEs themselves, that is, the extent to which FLEs' collaboration in NS cocreation is a stimulus for FLEs in terms of satisfaction, creativity, commitment to the organization, and generation of common knowledge (FLE outcomes). Prior research indicates that FLEs' satisfaction, empowerment, and commitment are crucial to their adoption of an innovative role (Lages and Piercy 2012; Ordanini and Parasuraman 2011; Sørensen et al. 2013), but the potential motivating benefits of treating FLEs as operant resources are still underexplored (Umashankar et al. 2011). From an external perspective, NS outcomes are captured by the perceived benefits of the NS among customers (customer outcomes) and the NS performance in terms of sales, market share, and profits relative to the firm's objectives (NS market performance). The explicit consideration for the first time in the literature of customer-related outcomes (Lages and Piercy 2012) enlarges our understanding of FLE co-creation effects under the customer-centric perspective suggested by S-DL.

Third, our model expands on the Ordanini and Parasuraman (2011) and Melton and Hartline (2013) framework, exploring two routes of FLE co-creation effects. The routes allow a deeper understanding of (1) how the NS performance measures interrelate, (2) the indirect effects of FLE co-creation, and (3) the relative importance of each path for achieving NS market performance (Fig. 1). The path labeled as resources route, following the S-DL consideration of FLEs and customers as operant resources, is inspired by the ServiceProfit Chain Model (Heskett et al. 1994). The path designated as operational route (Fig. 1) provides further empirical evidence on the impact of NSD speed on NS quality, which has been widely discussed in the literature (Stanko et al. 2012), although it has not been previously analyzed in the NS co-creation context (Carbonell et al. 2009).

Finally, by using a sample of knowledge-intensive business services (KIBS), the study contributes to the literature on service innovation success in business markets, which, despite the increasing importance of business services, has been overlooked in previous research (Weissenberger-Eibl and Koch 2007). KIBS are expert, ${ }^{2}$ private companies or organizations that rely heavily upon the professional knowledge of their workforce to provide specialized, intermediate services to the business processes of other organizations, including private and public sector customers (Miles 2005; Miozzo and Grimshaw 2005; Viljamaa et al. 2010). The study of service innovation success in KIBS is of particular interest due to the strong impact of KIBS' successful innovation in their customer firms' operations (Murray et al. 2009), and the competitiveness of developed economies (European Commission 2012). Thus, KIBS are innovative firms which also serve as carriers of innovation within the economy, contributing significantly to growth and innovation in the service sector (Javalgi et al. 2011; Shearmur and Doloreux 2013; Tai-Shan et al. 2013).

Moreover, labor qualification is the dominant factor for the service provision in KIBS (Miles 2005), which enlarges the potential contribution of FLE co-creation to these firms' service innovation success. Hence, KIBS develop consulting services where knowledge is the basic "input" (Strambach 2008). Accordingly, typical FLEs in KIBS are consultants who achieve a high degree of professional knowledge, that is, "knowledge or expertise related to a specific (technical) discipline or (technical) functional-domain" (Hertog 2000, p. 505) that is adapted to the customer firms' needs in a problem-solving process. By doing so, FLEs in KIBS involve an in-depth interaction with the firms' customers, leading to a cumulative learning process (Strambach 2008) that reinforces their value as key operant resources in service innovation. Additionally, to achieve the right transfer of knowledge for an optimal problem solution in service encounters, FLEs in KIBS usually need to develop non-routine activities and complex operations of an intellectual nature (de Brentani and Ragot 1996; Løwendahl 2005; Strambach 2008). FLEs in

\footnotetext{
$\overline{{ }^{2} \text { Typical KIBS }}$ sectors comprise hardware consultancy; software consultancy and supply; data processing; architectural and engineering activities and related technical consultancy; legal, accounting, book-keeping, and auditing activities; tax consultancy; market research and public opinion polling; and business and management consultancy. Some examples of KIBS firms include the Nielsen Company, Oracle Corporation, Fluor Corporation, and the aforementioned Accenture Limited, BT Global Services, HCL Technologies, and Rite-Solutions. Therefore, usual FLEs in KIBS are engineers, software developers, accountants, lawyers, auditors, architects, marketers, etc. Consulting services provided by KIBS sometimes lead to the development of new product solutions, as for example, a construction project developed by an engineering consultancy firm.
} 


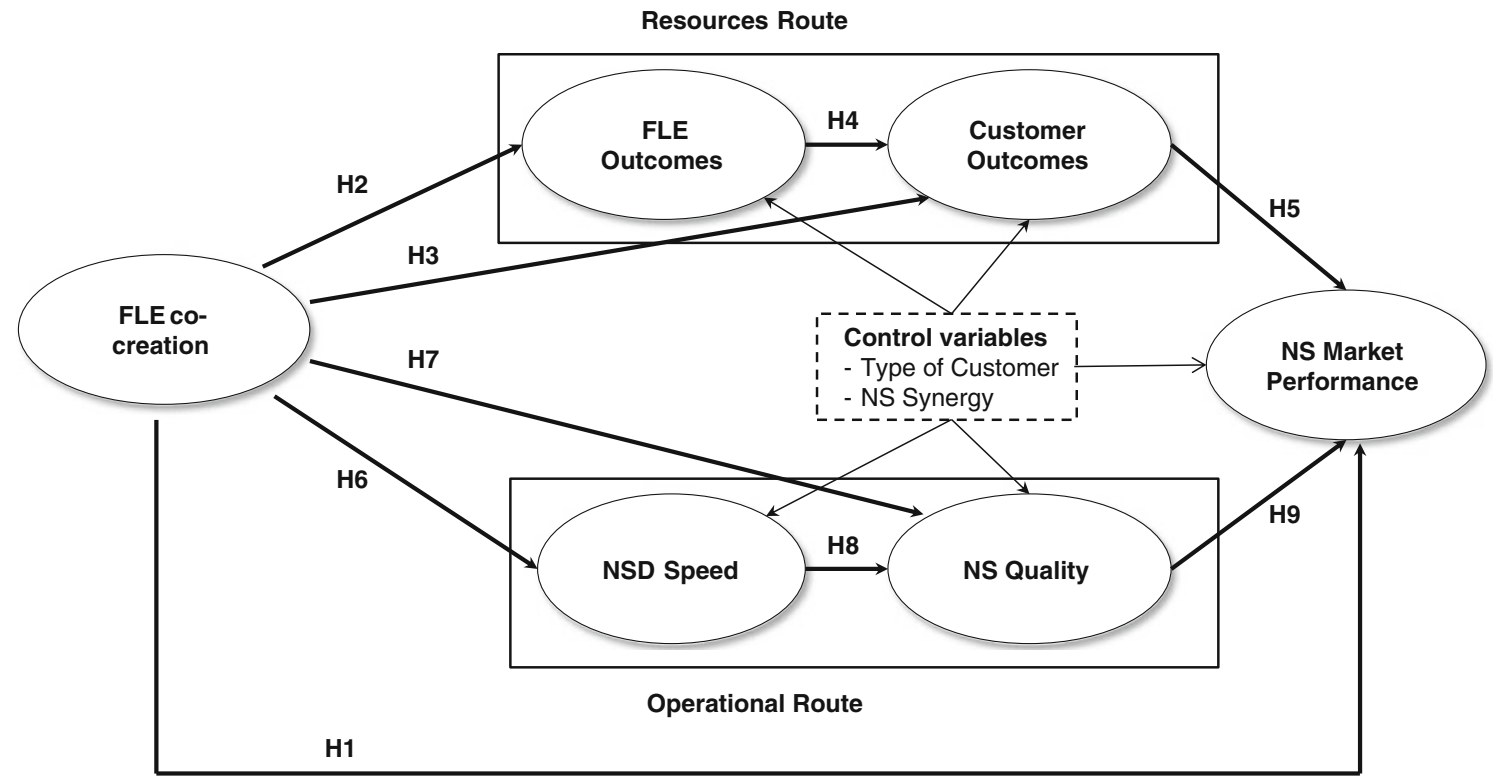

Key: NS = new service; NSD = new service development; FLE = frontline employee.

Fig. 1 Theoretical framework and hypotheses

KIBS, therefore, enjoy a higher degree of autonomy and empowerment than typical FLEs in the service context, facilitating their ability to take on an innovative role within the organization, and supporting their active collaboration NS cocreation (Ordanini and Parasuraman 2011; Sørensen et al. 2013).

The article is structured as follows. First, we review the literature on the FLEs' role in service innovation and investigate how the S-DL framework is applicable in the service innovation domain. Next, following the resources and operational routes, our study analyzes the potential effects of FLE co-creation on various NS performance indicators, as well as the interrelationships among them. In the empirical section, we introduce the methodology used in our research and present the findings. Finally, the article concludes with a discussion of the theoretical and managerial implications of this investigation, subsequently debating the limitations of the study and proposing future research opportunities.

\section{Theoretical framework and hypotheses}

\section{FLEs roles in service innovation}

Kesting and Ulhøi (2010) emphasize that all employees, in any organization, have hidden abilities for innovation and therefore typically constitute an underutilized innovation resource. These abilities are also reinforced by the fact that employees, during their daily activities, acquire exclusive and highly context-dependent knowledge, which managers often do not possess, and that can be exploited for the benefit of the firm in innovation processes. Innovations, accordingly, can emerge from any "ordinary" employee. However, the literature on service innovation also argues that in service organizations, as a logical consequence of how services are produced, delivered, and consumed, FLEs interact with the firm's customers on a regular basis and, in this way, they are in a privileged position for collecting, filtering, and translating useful customer information to identify uncovered market needs and anticipate future market trends (Bateson 2002; Lages and Piercy 2012; Melton and Hartline 2010, 2013; Schneider and Bowen 1984; van der Heijden et al. 2013). In this respect, Sørensen et al. (2013, p. 1446) define the service encounter-based innovation as "innovation that develops from ideas, knowledge, or practices derived (one way or another) from frontline service employees' meetings with users in the service delivery process." Thus, FLEs through service encounters can proactively ask consumers about their service experience and practices (van der Heijden et al. 2013; Ye et al. 2012) and obtain valuable insights from customer preferences and from future service improvement. Similarly, FLEs are, in many cases, the first to identify and repair service failures, actions that may also constitute the cornerstone of future required service innovations (Santos-Vijande et al. 2013a; Jayasimha et al. 2007; van der Heijden et al. 2013). FLEs thus constitute a key mechanism for accumulating experience and knowledge about customers, as well as becoming a key source of creative ideas for steering the design of future service innovations (Melton and Hartline 2010, 2013). Moreover, FLEs also accumulate supply-side knowledge (Magnusson 2009), that is, knowledge relative to their work domain and procedures that is extremely valuable for 
understanding how NS ideas can be implemented in practice. FLEs, therefore, are capable of looking at the NS idea from the company's perspective in terms of feasibility, including both technical and organizational issues (Engen and Magnusson 2015), which enriches their contribution to the service innovation process. In sum, FLEs constitute an essential source of information needed to direct the design and implementation of new core and augmented services, and in this way have a key role in service innovation success.

The important role that FLEs play in service innovation is reinforced in KIBS, because these firms rely strongly on professional knowledge and skills that are deeply embodied in human capital (Cavusgil et al. 2003; Freel 2006; Nätti and Ojasalo 2008). Accordingly, FLEs in KIBS are highly qualified, usually experienced professionals who achieve a high level of personal interaction with the firm's customers, linking their respective professional and industry-specific knowledge in order to provide complex services (Thakor and Kumar 2000). These practices increase the opportunity for FLEs to become the employees most familiar with the market's latent needs and to envision future service innovations (de Brentani and Ragot 1996). Furthermore, FLEs in KIBS possess the expert knowledge that ultimately determines the quality of the service provided, and that is crucial for the design of comprehensive innovations for the market (Landry et al. 2012; Sørensen et al. 2013). In this context, FLEs' human capital represents a key strategic asset in KIBS that is increasingly required to take part in the creation of service innovations (Corrocher et al. 2009).

In the discussion of FLEs' roles in service innovation, Sørensen et al. (2013) propose a categorization of service "encounter-based" innovation processes that involves two broad approaches: (1) a top-down push approach, wherein the NS development is intentionally initiated by senior management, marketing, and/or R\&D departments, building from FLEs' ideas but maintaining consistency with the organization's strategic concerns, and (2) a bottom-up pull approach, which means that the NS arises from FLEs' creative practices in a problem-solving context. The latter involves practicebased adjustments, which mostly require small changes that need to be recognized and accepted at the organizational level (which usually takes place retrospectively) to develop them further and to reproduce them as innovations in new situations.

FLEs' input is relevant for service innovation in both "encounter-based" processes (Sørensen et al. 2013). Thus, an NS strategically initiated and controlled by managers in back offices (top-down push approach) is developed because users ask FLEs for new or improved services and/or because FLEs detect a new demand or identify a new potential service idea. Similarly, service practice-based innovations clearly depend on FLEs' creativity. Engen and Magnusson (2015) contribute to the categorization of service encounter-based innovation processes by observing that service "ad hoc innovations," defined as "a solution to a particular problem posed by a given client" (Gallouj and Weinstein 1997, p. 549), are not the result of a top-down planned strategic process, but may involve the commitment of a significant amount of organizational resources. In these cases, ad hoc innovations must be accepted by managers in back offices, as they are in control of the organizational resources to implement these ideas and can evaluate their compliance with the firm's strategic objectives. Accordingly, service innovation derived from service encounters may be planned and structured, non-intentional or nonsystematized, or both (Engen and Magnusson 2015).

Some examples in the KIBS context illustrate the FLEs' input in service encounter-based innovation. ${ }^{3}$ Futuver is a mid-size Spanish firm that provides a wide range of management and information technology consulting services. A decade ago, Futuver's FLEs detected a gap in the software tools for project management that were available in the market; these tools did not incorporate the procedures established by the most popular quality management standard prevailing at that time, the norm ISO 9001:2000. Almost at the same time, one of the firm's customers, Prodintec, an innovation and technology center, raised the need to have a specific tool for management of research, development, and innovation (R\&D\&I) projects that would be in line with the prevailing Spanish quality management standards in the innovation domain, the family of norms UNE 166000:2006. Therefore, Futuver's FLEs quickly envisioned the possibility of developing a new software tool to facilitate management of the organization's projects. The tool would incorporate quality management principles and, moreover, would be specially adapted for development of R\&D\&I activities. The NS idea was initially analyzed by Futuver's senior management, who approved its implementation as it was aligned with the firm's competitive strategy. In this way, based in FLEs' ideas, Futuver initiated a top-down push, encounter-based innovation processes that concluded with the market launch of one of the firm's core services, IDINET ${ }^{\circledR}$.

In a similar vein, Fluor Corporation (one of the world's leading engineering, procurement, construction, maintenance, and project management companies) followed a top-down push approach for the development of two new supplementary services (Lovelock and Wright 2001) that extend the core engineering consulting services provided by the firm. Thus, from FLEs' ideas, the firm designed two different software tools that allow measurement of (1) the safety level in any engineering project at any time, even though there are no accidents/incidents ("Safety Management Database"), and (2) the management of unexpected changes in projects,

\footnotetext{
$\overline{{ }^{3} \text { Further details }}$ of these case studies are available from the authors upon request.
} 
avoiding delays and conflicts with the customer firm ("Change Management Tool”).

On the other hand, ITK Ingeniería, an engineering and consultancy services firm that operates in the energy sector (among others), developed an ad hoc innovation that can be reproduced in new situations. Thus, one of ITK's customers, E.ON Spain (a division of the E.ON Group, which is one of the world's largest investor-owned energy suppliers) faced the need to revamp a spillway gate at an old dam, preferably without dewatering the reservoir so that they could avoid loss of revenue. E.ON Spain's first solution idea was to work underwater. Although this approach initially sounded feasible, after further detailed study of the problem ITK's FLEs identified several difficulties and disadvantages related to costs and security of working conditions. However, ITK's FLEs devised a new technical solution: a method that avoided dewatering the reservoir and that also allowed significant improvement in safety, quality, and environmental protection. After a detailed evaluation of the NS idea, ITK's senior management approved the new project. A key feature of the final solution achieved is its suitability to be used in any dam with a similar configuration of spillways.

\section{S-DL and service innovation}

Prior research has analyzed service innovation mainly from an assimilation approach, assuming that innovation drivers are similar in the product and service contexts and, to a lesser extent, from a demarcation approach, assuming that services are a special type of goods (i.e., intangible goods, with distinctive features), which limits generalization of the results (Ordanini and Parasuraman 2011). Both approaches, in any case, are inspired in a goods-dominant logic, as the service concept and its innovation process are inherently subordinated to physical goods (Michel et al. 2008; Ordanini and Parasuraman 2011; Skålén et al. 2015).

However, the S-DL (Vargo and Lusch 2004, 2008) provides a new framework for studying service innovation that builds from three basic premises: (1) service is the central mechanism for economic exchange, that is, service is exchanged by service; (2) service is based on the joint application of specialized competences (i.e., skills and knowledge) by the firm and any other relevant actors (e.g., customers, employees, or business partners), which represents a shift from static resources (such as plants and equipment) to dynamic or operant resources (people's knowledge and skills) (Edvardsson et al. 2012; Lusch et al. 2007); and (3) service is provided directly to other market participants or is provided indirectly through tangible goods (Vargo and Lusch 2004). Accordingly, both services and tangible goods can be understood as a constellation of resources and can therefore be encompassed under S-DL principles, which provides a synthesis approach for examining service innovation (Drejer 2004; Ordanini and Parasuraman 2011; Skålén et al.
2015). From this perspective, service innovation is defined as the result of the integration of operant resources in order to provide new or enhanced value propositions from the customers' viewpoint (Skålén et al. 2015).

In this way, the principles of S-DL (Vargo and Lusch 2004, 2008) offer a conceptual framework for supporting the suitability of FLEs' active collaboration in service innovation development from their consideration as relevant operant resources. Thus, from the S-DL perspective, operant resources are the fundamental source of competitive advantage (Vargo and Lusch 2004) as they "enable firms to make value propositions" (Karpen et al. 2012, p. 29) and, therefore, to innovate providing NS solutions. Following this line, Melton and Hartline (2013, p. 68) state that "a firm achieves competitive advantage as a function of how well it uses its operant resources to respond to needs of the market relative to how other firms use their operant resources." The inseparability of most services, which involves intense supplier-customer interactions during simultaneous production and consumption processes, allows FLEs to collect relevant knowledge about the service itself and the customers' preferences. The knowledge and skills of individual employees transform them into valuable operant resources on which firms can draw to enhance their ability to provide novel value propositions adapted to market needs and to improve NS performance (Edvardsson et al. 2012; Melancon et al. 2010; Melton and Hartline 2010, 2013; Ordanini and Parasuraman 2011).

In other words, service innovation is based on the continuous renewal, creation and transformation of key information and knowledge (Ordanini and Parasuraman 2011), and the collaboration of FLEs in the various stages of the NSDP contributes to the process becoming a significant driver of service innovation success. Thus, FLE co-creation allows transfer of FLEs' customer and market knowledge to the firm and the deployment of their skills in the NSDP, thereby building firm's adaptive and absorptive competences that yield to superior service innovation performance (Lusch et al. 2007; Melancon et al. 2010; Melton and Hartline 2013; Ordanini and Parasuraman 2011). From an S-DL perspective, FLEs not only constitute a valuable source of NS ideas but also are critical actors to jointly collaborate along the NSDP with the firm's internal development team.

In the case of both Fluor and Futuver, the internal team responsible for the development of new software tools was integrated by software developers. In the case of ITK, the $R \& D$ department was in charge of new engineering consultancy projects. FLEs at Fluor and ITK were primarily consultant engineers; Futuver's FLEs mainly include process management, quality, and innovation consultants. In all three firms, FLEs actively worked with their respective development teams to achieve joint production of service innovations and to facilitate their market launch. To this end, FLEs kept frequent meetings and participated in joint tasks with the team's members, and were consulted on a regular basis about 
the NS. In this way, Futuver's and Fluor's FLEs participated actively in the design of all utilities of the new software tools developed in each firm. ITK's FLEs engaged in the calculation of the costs and the economic viability of the project, as well as in the development of the complex engineering design and the construction activities required by the NS. In all cases FLEs offered guidance and engaged in the commercialization of the service innovations becoming their first advocates.

Despite the S-DL consideration of FLEs as operant resources that can serve as a critical source of innovation knowledge, to become valuable operant resources, FLEs need to be empowered and enjoy a supportive and participative work environment that does not penalize them for failed ideas (Ordanini and Parasuraman 2011). In this respect, Cadwallader et al. (2010) demonstrate that motivation at different levels (e.g., task autonomy or role clarity) exerts a significant direct and indirect effect on FLEs' engagement in service innovation implementation. Similarly, Lages and Piercy (2012) prove the importance of perceived organizational support in fostering the FLEs' generation of ideas for service improvement. Sørensen et al. (2013) conclude that FLEs' ability to act as corporate entrepreneurs depends on how effectively organizations facilitate creativity by means of an adequate front-office innovation climate, and how capably they integrate the results of this creativity (innovative ideas or practices) through adequate organizational support systems. Likewise, Engen and Magnusson (2015) reinforce the importance of middle management roles in facilitating FLEs' ability to create NS ideas and to engage in service firms' innovative processes.

In the case of KIBS, FLEs rely on their professional experience and expertise when they respond to customers' problems, and in so doing they enjoy a relatively autonomous status that empowers them to make decisions for solving customer problems. For this reason, in these firms it is common to find sector-wide codes of ethical behavior, instituted to prevent opportunism in the necessary autonomy of professional practices (de Brentani and Ragot 1996; Løwendahl 2005). KIBS firms are also fully aware that the continued involvement and commitment of FLEs, as the persons whose vision and specialized capability support the professional service, is critical to assure the firms' continued creativity and reputation for expertise (de Brentani and Ragot 1996). Accordingly, FLEs in KIBS receive special consideration and support as key resources (Corrocher et al. 2009) in order to facilitate the transfer of knowledge and the firm's innovation capability (Cavusgil et al. 2003). Higher levels of autonomy and empowerment of FLEs in KIBS, together with the special consideration that these employees receive as key organizational resources, can facilitate FLEs' greater willingness to collaborate in service innovation, and guarantee the effectiveness of FLE co-creation practices. In any case, it is crucial for KIBS firms to develop a strong management commitment toward the cocreation capabilities of FLEs as an important antecedent of
FLEs' predisposition to participate in the NSD process (Santos-Vijande et al. 2013b).

The previous discussion of the potential benefits of FLE cocreation, together with the S-DL framework for service innovation analysis, affirms FLEs as key operant resources that accumulate valuable skills and external market knowledge in order to uncover market needs and anticipate future market trends. Accordingly, FLE co-creation activities can be expected to allow design of a more successful NS offering in the marketplace, in terms of sales, profits, and market share. Thus, we hypothesize:

H1: FLE co-creation directly and positively affects NS market outcomes.

In this sense, the three firms participating in the case studies agreed that FLE co-creation was beneficial for NS market performance. Fluor also underlined the positive impact of FLE co-creation on the perceived benefits of the service innovations among customers (customer outcomes); thus, the new software tools for project management contributed significantly to the provision of added value for the firm's customers, as well as to the firm's commercial image and market leadership. Futuver emphasized the benefits of FLE co-creation in terms of the technical and functional quality (NS quality) achieved by $\operatorname{IDINET}^{\circledR}$, which is currently used by more than 2000 organizations in different countries. ITK highlighted the reduction in NS costs and time to market (NSD speed) achieved through FLE co-creation. In all cases, the firms underlined the motivating effects of co-creation practices among their FLEs (FLE outcomes). Accordingly, the next section discusses further benefits of FLE co-creation and the interrelationships among the NS performance measures considered.

\section{The resources route}

\section{FLE co-creation and FLE outcomes}

The literature suggests that FLE co-creation improves FLEs' positive attitudes toward innovation, as well as their satisfaction with the NS and their commitment to the firm (Melton and Hartline 2010, 2013). Thus, as service innovation affects FLEs' roles, requiring in many cases changes in behavior and the development of new knowledge (Cadwallader et al. 2010), the collaboration of FLEs in the NSDP allows a strong involvement with service innovation from its initial stages and helps reduce resistance to the "unknown" (Nijhof et al. 2002). In this way, the firm can achieve ready internal adoption of service innovation due to FLEs' favorable perceptions of the innovation process and the service innovation (Korhonen and Kaarela 2011).

Additionally, although innovation activities are primarily the responsibility of a small group of individuals in most organizations (top managers and/or R\&D personnel), and the majority of "ordinary" employees are typically excluded from these 
activities (Kesting and Ulhøi 2010), modern firms must understand that employees want to be recognized as valuable organizational resources, with the ability to actively engage in the firm's operations and to contribute, with their own expertise, creativity and professional talent, to the improvement of firms' processes (Cadwallader et al. 2010). Therefore, soliciting FLEs' input in the service innovation process is likely to have a strong motivating effect on FLEs by enhancing their perceptions of the extent to which the firm values their contributions (Bell and Menguc 2002; Umashankar et al. 2011). FLE co-creation can also help to attract and retain the best human talent, due to the satisfaction created by the possibility of collaborating in the firm's innovative activities (Kesting and Ulhøi 2010; Melton and Hartline 2013; Umashankar et al. 2011). Such reasoning may be especially true in advanced business services that are characterized by a high proportion of professionally qualified staff (Korhonen and Kaarela 2011; Rubalcaba et al. 2008).

Based on the benefits of FLE co-creation that have been discussed, we expect that the NS obtained from the cocreation process helps to improve FLEs' satisfaction and serves as a stimulus to FLEs, to the extent that it incorporates their inputs. Similarly, the NS is expected to foster FLEs' creativity and commitment to the organization throughout a more satisfactory implementation process. We also understand that the NS obtained from FLE co-creation practices can help to increase FLEs' motivation, which is understood as the "degree to which a person wants and chooses to engage in specified behaviors" (Cadwallader et al. 2010, p. 220), to develop the firm's common knowledge valuable for service innovation. In this study, these variables are referred to as FLE outcomes. For this reason, we state that:

H2: FLE co-creation directly and positively affects FLE outcomes.

\section{FLE co-creation and customer outcomes}

The firm's FLEs accumulate increasingly sophisticated skills, which make them valuable resources for guiding the innovation development processes by making collaborative use of their market knowledge and skills (Kesting and Ulhøi 2010). This is especially true in KIBS firms because of the professional qualifications of their FLEs.

Indeed, the involvement of FLEs in the process of developing service innovations can provide the firm's customers with various types of benefits. First, being in direct contact with customers, FLEs are an invaluable source of information about latent market needs. The firm can then anticipate the development of high added-value innovations (Cadwallader et al. 2010; Jayasimha et al. 2007; Østergaarda et al. 2011), which will be quickly accepted and adopted by customers (Melton and Hartline 2010; Schneider and Bowen 1984).
Second, FLEs in service organizations are the first to identify and make adjustments to avoid potential service failures, which in turn can provide the basis for needed future innovations (Santos-Vijande et al. 2013a; Jayasimha et al. 2007). Accordingly, with their knowledge and experience, FLEs' collaboration in the NSDP can contribute to enhancing customers' utility when they adopt the service innovation and facilitate the anticipation of potential problems with the NS.

Moreover, FLE co-creation also allows improvements in the NS delivery process, by early incorporation of other relevant information. Thus, FLE co-creation can help firms to estimate the extent to which the NS fits their existing human resources and, thereby, to identify the employee training needs that may be required to construct the knowledge and skills necessary for making full use of the service (Schneider and Bowen 1984), and to facilitate a more successful service experience from the customer's viewpoint. In other words, FLEs influence the customer experience on a daily basis, and they usually play a key role as the driving force behind successful service encounters. It is crucial that FLEs have an adequate knowledge base for successful provision processes (Melancon et al. 2010), as well as upgrading their competence when it is required by the NS. This process can be more precisely anticipated when FLE co-creation takes place.

Finally, FLE co-creation favors FLEs' adoption of the service innovation, leading to a much stronger commitment to the service provision process (Korhonen and Kaarela 2011). In sum, FLE co-creation is expected to have a favorable impact on customer-related performance indicators such as customer satisfaction, loyalty, and other perceived benefits, which are designated in this research as customer outcomes. We therefore posit:

H3: FLE co-creation directly and positively affects customer outcomes.

\section{FLE outcomes and customer outcomes}

The services literature suggests that FLEs play a key role in customer satisfaction (Clark et al. 2009; Gwinner et al. 2005; Hennig-Thurau et al. 2006; Marinova et al. 2008; Ye et al. 2007). Hence, in service contexts FLEs "are the service" (Zeithaml et al. 2009, p. 352), and they constitute a critical factor for the successful NS implementation. Additionally, the literature establishes that "service innovations will succeed only insofar as the employees embrace, execute, and promote them" (Cadwallader et al. 2010, p. 220). Therefore, FLEs' satisfaction with and commitment to the NS are essential for enhancing the NS benefits perceived by customers (Melton and Hartline 2010), as is also contended by the Service-Profit Chain model (Heskett et al. 1994). Accordingly, it is expected that the greater the FLE outcomes, the greater the extent of their contribution to creating satisfied customers and building long- 
term customer relationships (Umashankar et al. 2011). This link should be especially relevant in complex professional business services, as FLEs are determinants for the explanation and adaptation of service innovations for the customers, contributing in this way to the NS provision of added value (Rubalcaba et al. 2008). Therefore, it is expected that higher FLE outcomes will help to improve customer outcomes:

H4: FLE outcomes directly and positively affect customer outcomes.

\section{Customer outcomes and NS market performance}

The Service-Profit Chain model (Heskett et al. 1994) suggests that profit and growth in service firms are stimulated primarily by customer loyalty, which is a direct result of customer satisfaction. The underlying rationale to this relationship is that higher customer satisfaction levels lead to increased loyalty and lower price sensibility, which respectively reinforce future repurchase intentions and allow for higher prices. Satisfaction also results in an enhanced overall reputation of the firm that favors long-term relationships. Following this rationale, Bernhardt et al. (2000), using longitudinal analysis from a chain of fast-food restaurants, prove that customer satisfaction leads to a firm's higher profits. Similarly, Chi and Gursoy (2009) and Yee et al. (2008) find empirical evidence in the hospitality industry that supports this relationship. Accordingly, it is expected that this effect also occurs in the service innovation context, and that customer outcomes lead to higher NS market performance (Prahalad and Krishnan 2008). Prior research in the business services literature also provides empirical evidence to support this relationship (Santos-Vijande et al. 2012, 2013b). Therefore:

H5: Customer outcomes directly and positively affect the NS market performance.

\section{The operational route}

\section{FLE co-creation and NSD speed}

Innovation speed reflects the firm's capability to accelerate the NSDP (Chen et al. 2005), and it constitutes a key mechanism for achieving competitive advantage, as it enables greater responsiveness to user needs (Umashankar et al. 2011). Johne and Storey (1998) find that effective collaboration with service employees increases the NSD speed. Melton and Hartline (2010) provide compelling empirical evidence regarding the shortening effect on the NSDP of FLE co-creation. Thus, FLEs contribute appropriate ideas to meet customers' needs from the initial stages of the NSDP, avoiding later delays due to re-definition of service features. FLE co-creation can also reinforce the motivation and commitment of these employees to the NS (Umashankar et al. 2011), as well as their willingness to adopt and recommend the service innovation (Cadwallader et al. 2010). This facilitates the NS launch process and shortens the NS time to market. In this respect, when the service is complex, as with KIBS firms, the service supplier role is of vital importance to facilitate the customers' adoption of the service innovation (Crosby et al. 1990). This means that FLEs involved in the NS co-creation are in an optimal position to explain service innovations to customers, and to facilitate the commercialization of the NS. Based on the above arguments we expect that:

H6: FLE co-creation directly and positively affects NSD speed.

\section{FLE co-creation and NS quality}

Service quality reflects the extent to which the service meets customers' expectations (Zeithaml 1987). Grönross (1982) identifies two main dimensions of service quality: technical quality ("what" is provided, or outcome), and functional quality ("how" it is provided, or process). Melton and Hartline (2010) contend that FLEs hold a unique position from which to obtain insights into customers' preferences and to determine the most suitable service delivery processes from the customer's viewpoint. FLEs therefore constitute a key resource for identifying customers' needs (Ordanini and Parasuraman 2011) and define both the firm's core and support service attributes from a market value perspective (Cadwallader et al. 2010). Hence, FLE co-creation is likely to improve the technical quality of the NS in terms of superior service value relative to customer expectations. Similarly, as FLEs are critical for service delivery, their participation in decision making during the NSDP may also have direct repercussions on the functional quality of the service experience in terms of improved provision processes. In this respect, Cadwallader et al. (2010) argue that FLEs' participation in service design improves their qualification to perform the $\mathrm{NS}$, as well as improving the quality of the provision process. Based on their previous experience, FLEs can achieve a superior understanding of NS delivery process specifications, and can then anticipate the type of support systems that may be required to improve the NS provision (Melton and Hartline 2010; Schneider and Bowen 1984; Umashankar et al. 2011). Accordingly, FLE co-creation is expected to contribute to the technical and functional quality of the NS, as well as to lowering the frequency of complaints (Jayasimha et al. 2007; Umashankar et al. 2011). Therefore:

H7: FLE co-creation directly and positively affects NS quality. 
NSD speed and NS quality

Recent studies in the innovation literature, mainly referring to product innovation, have focused on innovation process speed and new product quality as forerunners of innovation performance (Carbonell and Rodriguez 2006, 2010; Carbonell et al. 2009; McNally et al. 2011), as well as on the innovation speedquality relationship (Chen et al. 2005; Lukas and Menon 2004; Stanko et al. 2012). In this respect, the literature presents conflicting results regarding the speed-quality interface, which has not been previously analyzed in the context of service innovation co-creation. Some authors consider that rapid innovation may be detrimental to quality, especially when speed is made the prime objective for the firm, suggesting that deadline pressures would result in fewer checks on the innovation process (Chen et al. 2005). Indeed, such pressures can also trigger stress behaviors in the staff, which may also adversely affect the quality of the innovation process (Lukas et al. 2002). Other authors suggest that the relationship between innovation speed and quality may be an inverted U-shape (Lukas and Menon 2004). Hence, too much and too little speed can lead to the NS having lower quality. A third group of authors believe that there is a positive relationship between NSD speed and NS quality. In particular, they argue that NSD speed means that the offer is more up-to-date, as the process is able to both incorporate the latest technical advances and respond to the latest needs of the market in terms of what and how is offered (Carbonell et al. 2012; Kessler and Bierly 2002). Under this assumption, only in very extreme cases with very short development times would quality be affected negatively. Also, a reasonable development speed helps to enhance focus and discipline in the development effort, reinforcing the quality of the innovation being developed (Lukas and Menon 2004; Stanko et al. 2012).

From this third perspective, Stanko et al. (2012) demonstrate that faster innovation processes allow the ready incorporation of both market information and customer feedback, thus improving the innovation quality. As a result of NSD speed, firms can provide in advance a service offering that is adapted to the market demands and preferences and which is perceived as clearly different from any alternative offered by the competition (Alam 2006; Lin and Germain 2004); in sum, of higher quality from the customers' viewpoint. Stated more formally:

H8: NSD speed directly and positively affects NS quality.

\section{NS quality and NS market performance}

The relationship between NS quality and NS market performance in terms of sales, profits, and market share has been dealt with extensively in the service innovation literature (Atuahene-Gima 1996; Avlonitis et al. 2001; Cooper et al. 1994; de Brentani 1991, 2001; Storey and Easingwood
1996, 1998). Greater NS quality yields an improved NS market performance by offering the final customer superior value and a better service experience, which in turn supports improved sales volume and market share (Ngo and O'Cass 2013), and allows premium prices to be charged, which leads to higher profits (Zhou et al. 2008). Similarly, de Brentani and Ragot (1996) also find that professional service firms that promise and deliver excellent service outcomes from the customer's perspective do achieve improved success, which has been further confirmed in recent studies (Santos-Vijande et al. 2013a). Hence, we posit:

H9: NS quality directly and positively affects NS market performance.

\section{Routes' mediating effects}

The conceptual model in this study, supported by the literature, shows the direct impact of FLE co-creation in five different performance measures; however, the two performance routes considered also indicate the presence of mediating effects that have not been extensively researched. Thus, from a broad perspective, the resources route and the operational route mediate the effect of FLE co-creation on the NS market performance, reflecting in each case a double mediating effect exerted, respectively, by FLE outcomes and customer outcomes (resources route), and by NSD speed and NS quality (operational route). Additionally, within each respective route, two further mediating effects can be observed, and which are exerted in the resources route by FLE outcomes (FLE cocreation $\rightarrow$ FLE outcomes $\rightarrow$ customer outcomes) and customer outcomes (FLE outcomes $\rightarrow$ customer outcomes $\rightarrow$ NS market outcomes), and in the operational route by NSD speed (FLE co-creation $\rightarrow$ NSD speed $\rightarrow$ NS quality) and NS quality (NSD speed $\rightarrow$ NS quality $\rightarrow$ NS market outcomes).

The Service-Profit Chain model (Heskett et al. 1994) provides a conceptual support for the mediating effect of the resources route as a whole, as well as for the two intermediate mediating effects. The Service-Profit Chain depicts a chain of effects from the internal service quality (which is intrinsically related to employee support and recognition, among other factors) to more satisfied employees who provide better services, that is, a more satisfactory service experience for the customer, which ultimately leads to improved service market performance. FLE co-creation involves valuation, recognition and empowerment of employees, and may therefore trigger the chain of effects through the FLEs' satisfaction to both customer outcomes (simple mediation) and to the NS market performance (double mediation). Chi and Gursoy (2009) find that customer satisfaction fully mediates the impact of employee satisfaction on service financial performance, which 
supports the mediating role of customer outcomes in the FLE outcomes-NS market performance relationship.

The operational route double-mediating effect is supported in the notion that key service-intrinsic characteristics, such as NSD speed and NS technical quality, influence NS market outcomes (Tatikonda and Montoya-Weiss 2001). In this respect, Carbonell et al. (2009) find that NS quality and NSD speed fully mediate the impact of customer co-creation in NS market performance. To the extent of our knowledge, the mediating effect of NSD speed in the FLE co-creation-NS quality relationship has not been previously tested. However, given that FLE co-creation allows a more accurate definition of customers' needs, thereby leading to improved NS quality (direct effect, H7), it can also be argued that FLE co-creation allows faster satisfaction of potential market needs relative to the competition, which reinforces the customers' perception of service quality and substantiates the mediating effect of NSD speed. Finally, Stanko et al. (2012) do not find a direct relationship between speed to market and new product profitability, this relationship is mediated by new product quality. This evidence supports the mediating role of NS quality in the NS speed-NS market performance relationship. Accordingly, the following hypotheses are posed:

H10: IFLE co-creation impacts indirectly, mediated by FLE outcomes and customer outcomes (resources route), on NS market performance: (a) FLE outcomes mediate the indirect effect of FLE co-creation on customer outcomes, and (b) customer outcomes mediate the indirect effect of FLE outcomes on NS market performance.

H11: FLE co-creation impacts indirectly, mediated by NSD speed and NS quality (process route), on NS market performance: (a) NSD speed mediates the indirect effect of FLE co-creation on NS quality, and (b) NS quality mediates the indirect effect of NSD speed on NS market performance.

\section{Methods}

\section{Sample and data collection}

We tested the conceptual model using a sample of KIBS. These firms, as intermediaries and input providers for many other economic agents' innovation processes, constitute one of the main engines for future growth in developed countries (European Commission 2012; Javalgi et al. 2011; Shearmur and Doloreux 2013; Tai-Shan et al. 2013). To carry out the empirical study, we used the SABI (Iberian Balance Analysis System) database to pinpoint the target population. The NACE codes that we considered for identifying KIBS sectors were the same that the European Monitoring Centre of
Change (EMCC 2005) uses in its studies. A stratified random sampling procedure identified a population of 1587 firms with more than 10 workers. Data were collected using a structured questionnaire.

This investigation belongs to a broader study about operations of service firms which made advisable the consideration of General Managers and Managing Directors as key informants. General Managers and Managing Directors represent executive positions that receive information from a wide variety of departments or areas within the company; thus it is reasonable to think that these respondents were knowledgeable and competent to provide information about their firm's activities and performance outcomes (Arnold et al. 2011; Ordanini and Parasuraman 2011; Thorpe and Morgan 2007). Data from other managers below the top level may also "have validity issues because such managers generally do not have access to information about how the total system operates" (O'Cass and Weerawardena 2010, p. 575). Moreover, our informants have been employed in their respective firms, on average, for more than 9.5 years. The use of similar key informants with similar levels of influence also increases the validity of the measurements of the variables (Aragón-Correa et al. 2007). Furthermore, most of the KIBS firms included in the study have fewer than 250 employees, and can therefore be regarded as small- and medium-sized enterprises (SMEs). In this type of organization, senior management's level of access to and control of strategic information can be considered to be very high, which was further confirmed during the pre-test of the questionnaire among $14 \mathrm{KIBS}$ firms.

Key informants were asked to provide detailed information about a relevant or significant NS development project undertaken by their firm in the preceding 3 years (Carbonell and Rodríguez 2010; Joshi and Sharma 2004; Santamaría et al. 2012; Stanko et al. 2012). The project's relevance guarantees that the NS involved a certain innovative effort, which favors the respondents recall as well as knowledge of the NS at toplevel management. The time frame ensures the quality of the information acquired, that is, that the firm had sufficient data on the resulting performance outcomes. Moreover, the questionnaire clearly indicated to the respondents that the section about service innovation practices would entail providing information about a specific NS development and that, in case they were not familiar with these practices, this section should be answered by the most suitable person in the firm to provide this information. In this case, the name and position in the organization of the new respondent was required. Only four questionnaires were answered by a different informant, mainly the manager in charge of the project, so we were confident that in the remaining sample firms the General Manager or Managing Director was familiar with the NS development. In a similar vein, Melton and Hartline (2013) point out the difficulty of identifying the executives responsible for NS development and compile a list of key contacts likely to have responsibility for and extensive knowledge of service 
innovation activities in organizations, including each firm's president, among others.

KIBS managers also evaluated the NS performance among customers. KIBS, as business firms offering complex services, develop very close relationships with their customers as part of their standard service-providing procedures (Thakor and Kumar 2000). Consequently, KIBS managers are capable of a more solidly founded assessment of results among their customers in a specific period. Most of the firms in the sampled companies were ISO 9001:2000 certified, which ensures that they have in place iterative procedures for evaluating their customers' and employees' satisfaction and performance, as it is required for this certification. Moreover, studies in the service innovation literature frequently measure variables such as NS quality (Ngo and O'Cass 2013) or new product quality (Stanko et al. 2012) as perceived by managers.

Each firm was contacted by telephone to: (1) give prenotification of the purpose, relevance, and execution of the research, (2) determine the firm's initial availability and suitability to participate in academic research, and (3) verify the key informant's name, position, and contact details. This procedure resulted in the removal of 351 firms from the sample. The most common reasons were the cessation of activity due to the recent economic crisis, inaccuracies in the firm's data, and resistance to collaborating in an external investigation. The questionnaires were sent by e-mail, fax, or ordinary mail according to each respondent's preference. The delivery was followed up by contacting the firm again, twice if necessary, to ensure that the questionnaire had been received, and to increase the response rate.

A total of 246 valid responses were obtained, equivalent to a response rate of $19.9 \%$ (of the 1236 questionnaires sent out). Organizations that did not complete the questionnaire indicated lack of time as the main reason. The firms in the sample were distributed by sector as follows: (1) IT services: $17.07 \%$ (NACE code 72); (2) management, legal, or accounting consultancies: $11.38 \%$ (NACE codes 74.11, 74.12, and 74.14); (3) engineering, architecture, and environmental consultancies: $40.65 \%$ (NACE code 74.20 ); (4) market research, advertising, and personnel recruitment and training consultancies: $7.72 \%$ (NACE codes 74.13, 74.4, and 74.5); and (5) miscellaneous business activities: $23.18 \%$ (NACE code 74.8 ). There were no responses in the R\&D sector (NACE code 73).

We also tested the mean responses of all the manifest variables of the survey instrument. Assessments carried out with Armstrong and Overton (1977) approach revealed that there were no significant differences between early (first quartile) and late (fourth quartile) respondents and, therefore, nonresponse bias cannot be considered a major concern in our study (Stanko et al. 2012).

Among the 246 KIBS firms participating in this study, 101 firms reported to have developed an NS project that involved the active collaboration of FLEs with the firm's internal development team along the different stages of the NSDP. Accordingly, only these firms answered the co-creation subsection of the questionnaire, so that the conceptual model was tested with this 101-firm subsample. In this respect, the literature acknowledges that service co-creation is in no way a straightforward activity and identifies several potential obstacles to FLE co-creation that may prevent these practices in KIBS (SantosVijande et al. 2013b). However, the lower number of responses raises the possibility of self-selection bias, especially because, in most cases, a single informant was considered in each firm. For this reason, we compared demographic characteristics of the 101-firm subsample (industry sector, seniority of the firm and the number of employees) with those of all the responding firms (Cuddeback et al. 2004; Hwang and Grant 2011). The results showed minimal differences in these indicators. Thus, only a slightly higher representation (confidence level, $90 \%$ ) of larger companies and consulting firms in engineering, architecture, and environmental issues was obtained.

We also attempted to control for the problem of common method variance by means of procedural and statistical techniques. Thus, we initially addressed the minimization of common method variance through study design (Hansen et al. 2013; Podsakoff et al. 2003, 2012): first, we included a psychological separation between predictor and criterion variables to prevent respondents to establish a causal relationship between these variables; second, we allowed respondents to preserve their anonymity when participating in the study; third, we also emphasized that no right or wrong answers exist, and that respondents should answer the survey questions as honestly as possible; fourth, we refined and improved item wording during the pre-test.

With reference to the statistical remedies applied (Hansen et al. 2013; Pavlou et al. 2007; Podsakoff et al. 2003, 2012), we first carried out Harman's single-factor test and found that no single factor accounted for more than $30 \%$ of the variance, which is below the $50 \%$ threshold set by Podsakoff and Organ (1986). Second, as Harman's single-factor test has insufficient sensitivity to identify small to moderate levels of common method variance (Malhotra et al. 2006), we employed a modified test based on Lindell and Whitney's (2001) markervariable technique. This is a suggested procedure for economizing survey items, as we did not measure ex ante an unrelated construct (Pavlou and Gefen 2005; Pavlou et al. 2007). In this regard, the firms' orientation to establish strategic alliances is used as a weakly related marker variable (Kandemir et al. 2006), represented by the item: "our firm seeks to establish strategic alliances for the commercialization of its service offer." The marker variable was included in the structural equation model and the variance of any of the dependent variables did not significantly increase. Furthermore, the average correlation between the marker variable and the constructs of the structural equation model is 0.084 and the average significance is 0.446 (bilateral), which is above the threshold of 0.05 
(bilateral) and 0.01 (bilateral) necessary to consider correlations as significant. The use of procedural remedies, together with the statistical tests carried out, led us to conclude that common method variance was not a problem in this study.

\section{Measurement scales}

We used multi-item scales to measure the constructs under analysis, and we used reflective indicators as measures of the model's variables. These scales are presented in full detail in the Appendix: Measurement scales. The perceptual responses for the constructs were measured using a 7-point Likert scale ranging from $1=$ strongly disagree to $7=$ strongly agree.

There is no consensus in the literature regarding the configuration of the NSDP or the number of stages that it must include; neither is there agreement about the possible similarities or differences between the processes of developing new products and services (Alam 2006). With these issues in mind, for this study we opted to consider six key stages in the NSDP. This choice was inspired by the earlier work of Alam (2002) and embraces the same phases considered in subsequent studies (Carbonell et al. 2009; Melton and Hartline 2010): idea generation, idea selection, business analysis, service and process development, market test, and market launch. To evaluate the extent of FLE co-creation in the NSDP, for each stage we asked about the richness and depth of FLEs' collaboration, using the following three items: (1) frequent meetings, (2) active participation in the development team, and (3) detailed consultations (Alam 2002; Gruner and Homburg 2000; Melton and Hartline 2010; Ordanini and Parasuraman 2011). In this study, FLE co-creation is conceptualized as a secondorder reflective construct. Therefore, service innovation cocreation is considered to occur if an extensive collaboration with FLEs is achieved during all the stages of the NSDP.

To determine the effects of NS co-creation on FLEs, we designed an original scale inspired by the work of Cadwallader et al. (2010), Melton and Hartline (2013), and Umashankar et al. (2011). These authors analyze the benefits of FLE cocreation and their findings reinforce the idea that this process is satisfying and motivating for FLEs themselves, leading to a more positive perception of the innovation process and the service innovation. Thus, the FLE outcomes scale assesses the degree to which the co-created NS improves FLEs' satisfaction, acts as a motivating stimulus for these employees, fosters their creativity and commitment, and contributes to their development of the firm's common knowledge.

Taking as referents recent studies on NS success (Carbonell et al. 2009; Hsu and Fang 2009; Lynn et al. 2000; Ngo and O'Cass 2013; Ottenbacher et al. 2006; Ottenbacher and Harrington 2008), the customer outcomes scale focuses on the customer's satisfaction, loyalty, enhanced firm image, and leadership as a consequence of the NS. The scale used to measure the NS market outcomes refers to NS sales, market share, and profits relative to the firm's objectives for the NS project, since relative measures facilitate the comparison of different innovation projects (Carbonell et al. 2009).

Innovation speed is defined as the pace of progress that a firm displays in innovating and commercializing a new offer. It describes a firm's capability to accelerate the activities and tasks that occur through the development process of an innovation (Carbonell et al. 2009; Chen et al. 2005). NSD speed was measured by means of three items taken from previous studies: time effectiveness (i.e., launching the NS on or ahead of schedule), time efficiency (doing the project faster than other competing alternatives), and time compared to what was considered customary for the industry (i.e., the ability to successfully carry out the NSDP in an agile and fast way) (Carbonell et al. 2009; Menor et al. 2002).

NS quality was measured from a technical and functional viewpoint, analyzing the extent to which the NS delivers superior customer value and the NS provision process minimizes failures and is performed in a superior way than competitors (Carbonell et al. 2009; Menor et al. 2002). In a similar vein to our approach, Ngo and O'Cass (2013) measure service quality using three items that encompass the technical and functional quality of the NS.

This study includes as control variables the type of customer participating in the co-creation process (e.g., Menor et al. 2002), as well as the NS synergy with the firm's resources (e.g., Huang and Tsai 2014). These control variables are expected to vary and to have potential direct effects on the five endogenous latent variables included in the model (Fig. 1). In this sense, a distinct feature of this study is that sample firms were asked to provide information about a NS co-created simultaneously with their FLEs and a customer firm. Thus, for example, NS co-creation in Futuver and ITK took place with the active collaboration in the NSDP of each firm's FLEs and a customer firm: Prodintec and E.ON Spain, respectively. Innovation co-creation with FLEs and firm's customers also takes place in Fluor on regular basis, although the company declined to provide detailed information in this respect. The conceptual model in this study refers to the potential benefits derived from FLEs co-creation. However, as we had available the profile of the customer firm also participating in NS co-creation, the type of customer is introduced as a control variable in the conceptual model.

The interest and ability to participate in co-creation processes vary greatly from one customer to another (Vernette and Hamdi-Kidar 2013). Even for those firms that have millions of potential customers, only a few will have a real desire to engage in innovation processes, or indeed, will have the skills to do so successfully (Etgar 2008; O'Hern and Rindfleisch 2010). Gruner and Homburg (2000) and Hoyer et al. (2010) present a typology of customers who may be more willing and able to engage in co-creation which, in both cases, includes the figure of "lead user customers." Based on 
these two works, we formulated the type of customer scale, which reflects lead users' characteristics in the customer firms.

A key factor in NS success is the synergy between the requirements of the NS and the resources of the firm (Melton and Hartline 2010). The literature confirms that new industrial service offerings that benefit from the firm's operating strengths and marketing facilities have a greater chance for success (Cooper and de Brentani 1991; de Brentani 1991; Ottenbacher et al. 2006). Based on these previous works, the NS synergy scale used in our study is shown in the Appendix: Measurement scales.

\section{Results}

In this study, we employed the partial least squares (PLS) approach for structural equation modeling (SEM), using the statistical package SmartPLS 3 (Ringle et al. 2014). We opted for the use of PLS-SEM over the statistical covariance-based methodologies for the following reasons (Barroso et al. 2010; Chin and Newsted 1999; Hair et al. 2011; Reinartz et al. 2009; Wold 1985): (1) because of the explorative nature of the study, where the emphasis is on the development of new theory; (2) because the number of observations is relatively small (the sample has 101 cases) and PLS does not require a large dataset; and (3) as PLS is a nonparametric technique, the data do not necessarily need to have a normal distribution. In the following, according to the methodological procedures suggested by Chin (1998), Hair et al. (2011), and Marcoulides and Saunders (2006), we a priori examine the measurement model results and then proceed with the analysis of the structural model.

\section{Measurement model}

The analysis carried out for the measurement model (reliability, convergent validity, and discriminant validity) suggests that all items are correct indicators of the latent variables. Indeed, for the first-order latent variables, as shown in Table 1, all loadings are above the threshold of 0.6 , and the associated $t$-statistic is statistically significant (Anderson and Gerbing 1988; Hulland 1999). The level of statistical significance for the associated t-statistic is computed by means of a bootstrap resampling method of 500 subsamples, with the same number of cases as in the original sample (Henseler et al. 2009). The values of the average variance extracted (AVE) range between 58.2 and $93.5 \%$, and the values of the composite reliability index (CR) range from 0.735 to 0.977 , thus indicating a satisfactory reliability for the latent variables (Bagozzi and Yi 1988). As confirmation of the existence of discriminant validity, for each pair of latent variables the square root of AVE exceeded correlations between the latent variables (Fornell and Larcker 1981). The correlation matrix, means, standard
Table 1 First-order and second-order measurement models

\begin{tabular}{|c|c|c|c|c|}
\hline Factor & Loading $^{\mathrm{a}}$ & AVE & $\mathrm{CR}$ & sqrt AVE \\
\hline FLE CO-CREATION (FLE_C) & & $55.4 \%$ & 0.880 & 0.744 \\
\hline $\begin{array}{l}\text { Idea generation (IG) } \\
\text { IG1 }\end{array}$ & $\begin{array}{l}0.760 \\
0.959\end{array}$ & $89.3 \%$ & 0.962 & 0.945 \\
\hline IG2 & 0.937 & & & \\
\hline IG3 & 0.940 & & & \\
\hline $\begin{array}{l}\text { Idea selection (IS) } \\
\text { IS1 }\end{array}$ & $\begin{array}{l}0.841 \\
0.970\end{array}$ & $90.1 \%$ & 0.965 & 0.950 \\
\hline IS2 & 0.965 & & & \\
\hline IS3 & 0.913 & & & \\
\hline $\begin{array}{l}\text { Business analysis (BA) } \\
\text { BA1 }\end{array}$ & $\begin{array}{l}0.789 \\
0.961\end{array}$ & $91.0 \%$ & 0.968 & 0.954 \\
\hline $\mathrm{BA} 2$ & 0969 & & & \\
\hline BA3 & 0.932 & & & \\
\hline $\begin{array}{l}\text { Service and process development (S\&PD) } \\
\text { S\&PD1 }\end{array}$ & $\begin{array}{l}0.770 \\
0.943\end{array}$ & $86.2 \%$ & 0.949 & 0.928 \\
\hline S\&PD2 & 0.931 & & & \\
\hline S\&PD3 & 0.910 & & & \\
\hline $\begin{array}{l}\text { Market test (MKT) } \\
\text { MKT1 }\end{array}$ & $\begin{array}{l}0.671 \\
0.968\end{array}$ & $93.5 \%$ & 0.977 & 0.967 \\
\hline MKT2 & 0.963 & & & \\
\hline MKT3 & 0.969 & & & \\
\hline $\begin{array}{l}\text { Market launch (MKL) } \\
\text { MKL1 }\end{array}$ & $\begin{array}{l}0.608 \\
0.950\end{array}$ & $90.0 \%$ & 0.964 & 0.949 \\
\hline MKL2 & 0.952 & & & \\
\hline MKL3 & 0.944 & & & \\
\hline $\begin{array}{l}\text { FLE OUTCOMES (FLEO) } \\
\text { FLEO1 }\end{array}$ & 0.852 & $77.9 \%$ & 0.934 & 0.883 \\
\hline FLEO2 & 0.909 & & & \\
\hline FLEO3 & 0.895 & & & \\
\hline FLEO4 & 0.872 & & & \\
\hline $\begin{array}{l}\text { CUSTOMER OUTCOMES (CO) } \\
\text { CO1 }\end{array}$ & 0.836 & $71.2 \%$ & 0.881 & 0.844 \\
\hline $\mathrm{CO} 1$ & 0.890 & & & \\
\hline $\mathrm{CO} 3$ & 0.804 & & & \\
\hline $\begin{array}{l}\text { NSD SPEED (NSD_S) } \\
\text { NSD_S1 }\end{array}$ & 0.701 & $69.7 \%$ & 0.862 & 0.835 \\
\hline NSD_S2 & 0.873 & & & \\
\hline NSD_S3 & 0.885 & & & \\
\hline $\begin{array}{l}\text { NS QUALITY (NS_Q) } \\
\text { NS_Q1 }\end{array}$ & 0.778 & $63.0 \%$ & 0.836 & 0.794 \\
\hline NS_Q2 & 0.734 & & & \\
\hline NS_Q3 & 0.863 & & & \\
\hline \multicolumn{2}{|l|}{ NS MARKET PERFORMANCE (NS_MP) } & $88.7 \%$ & 0.969 & 0.941 \\
\hline NS_MP1 & 0.946 & & & \\
\hline NS_MP2 & 0.954 & & & \\
\hline NS_MP3 & 0.954 & & & \\
\hline NS_MP4 & 0.911 & & & \\
\hline TYPE OF CUSTOMER (TC) & & $76.9 \%$ & 0.869 & 0.877 \\
\hline $\mathrm{TC} 1$ & 0.886 & & & \\
\hline $\mathrm{TC} 2$ & 0.868 & & & \\
\hline NS SYNERGY (NS_SY) & & $58.2 \%$ & 0.735 & 0.763 \\
\hline NS_SY1 & 0.794 & & & \\
\hline NS_SY2 & 0.730 & & & \\
\hline
\end{tabular}

${ }^{a}$ The criteria employed in PLS-SEM to consider an indicator to be suitable for a measurement scale is that of Chin (1998), Hair et al. (2011) and Hansen et al. (2013)

$A V E$ average variance extracted, $C R$ composite reliability, sqrt square root 
Table 2 Descriptive statistics and correlations

\begin{tabular}{|c|c|c|c|c|c|c|c|c|c|c|c|c|c|c|c|}
\hline & Mean & S.D. & 1 & 2 & 3 & 4 & 5 & 6 & 7 & 8 & 9 & 10 & 11 & 12 & 13 \\
\hline 1. IG & 4.436 & 2.055 & 0.945 & & & & & & & & & & & & \\
\hline 2. IS & 4.254 & 1.995 & $0.712^{* *}$ & 0.950 & & & & & & & & & & & \\
\hline 3. $\mathrm{BA}$ & 3.786 & 2.073 & $0.457^{* *}$ & $0.534^{* *}$ & 0.954 & & & & & & & & & & \\
\hline 4. S\&PD & 4.954 & 1.799 & $0.582^{* *}$ & $0.695^{* *}$ & $0.464^{* *}$ & 0.928 & & & & & & & & & \\
\hline 5. MKT & 3.465 & 2.171 & $0.322^{* *}$ & $0.394^{* *}$ & $0.551^{* *}$ & $0.321^{* *}$ & 0.967 & & & & & & & & \\
\hline 6. MKL & 3.858 & 2.129 & $0.221^{*}$ & $0.312^{* *}$ & $0.505^{* *}$ & $0.320^{* *}$ & $0.464^{* *}$ & 0.949 & & & & & & & \\
\hline 7. FLEO & 5.196 & 1.081 & $0.282^{* *}$ & $0.210^{*}$ & 0.022 & 0.135 & 0.184 & 0.098 & 0.883 & & & & & & \\
\hline 8. $\mathrm{CO}$ & 5.723 & 0.979 & $0.287^{* *}$ & 0.193 & 0.046 & $0.213^{*}$ & 0.044 & 0.180 & $0.521^{* *}$ & 0.844 & & & & & \\
\hline 9. NSD_S & 4.993 & 1.318 & 0.144 & $0.230^{*}$ & $0.278^{* *}$ & 0.121 & 0.137 & $0.224^{*}$ & $0.404^{* *}$ & $0.346^{* *}$ & 0.835 & & & & \\
\hline 10. NS_Q & 5.422 & 1.111 & $0.208^{*}$ & 0.159 & 0.073 & 0.170 & 0.095 & 0.195 & $0.584^{* *}$ & $0.460^{* *}$ & $0.606^{* *}$ & 0.794 & & & \\
\hline 11. NS_MP & 4.420 & 1.349 & $0.203^{*}$ & $0.216^{*}$ & 0.086 & 0.045 & 0.141 & 0.113 & $0.487^{* *}$ & $0.419^{* *}$ & $0.538^{* *}$ & $0.450^{* *}$ & 0.941 & & \\
\hline 12. TC & 5.227 & 1.416 & 0.050 & 0.044 & -0.081 & 0.055 & -0.071 & -0.107 & 0.179 & 0.189 & 0.071 & 0.093 & -0.073 & 0.877 & \\
\hline 13. NS_SY & 5.619 & 1.003 & 0.157 & 0.131 & 0.019 & 0.072 & $0.196^{*}$ & 0.088 & $0.257^{* *}$ & $0.448^{* *}$ & $0.272^{* *}$ & $0.443^{* *}$ & $0.203^{*}$ & 0.021 & 0.763 \\
\hline
\end{tabular}

Square root of the average variance extracted $(A V E)$ is in italics on the diagonal. Correlations are below the diagonal. The calculations of the correlation coefficients used the mean of the scores of the indicators that make up each of the latent variables

$I G$ idea generation, $I S$ idea selection, $B A$ business analysis, $S \& P D$ service and process development, $M K T$ market test, $M K L$ market launch, FLEO frontline employee outcomes, $C O$ customer outcomes, $N S D \_S$ new service development speed, $N S \_Q$ new service quality, $N S \_M P$ new service market performance, $T C$ type of customer, NS_SY new service synergy, S.D. standard deviation

deviations, and square root of the AVE of the thirteen firstorder latent variables are presented in Table 2.

The higher-order latent variable, that is, FLE co-creation, was created following a repeated indicators approach (Wetzels et al. 2009). By using this procedure, the second-order latent variable is specified with all (18) underlying indicators of the six first-order latent variables: idea generation, idea selection, business analysis, service and process development, market test, and market launch. The AVE and CR of the higherorder latent variable are included in Table 1. The AVE is $55.4 \%$, and the CR is 0.880 . As is also shown in Table 1 , loadings of the first-order latent variables on the secondorder latent variable exceed 0.6 , and the associated $t$-statistic is statistically significant. Finally, all measures were found to be reliable, as they exceeded the limits for acceptance.

One additional test was carried out to examine the reflective or formative nature of FLE co-creation: the vanishing tetrad test. Our approach coincides with the following extract in which "the assumption underlying the reflective model is that the correlations between the error terms, $\delta \mathrm{i}$, are zero. The vanishing tetrad test confirms whether or not this is true" (Coltman et al. 2008, p. 1254). Hence, we ran a vanishing tetrad test with the TETRAD IV program (Glymour et al. 2004) as well as with SmartPLS 3 (Ringle et al. 2014), using Bollen and Ting's (1993) approach. The empirical results in both cases lend support to the reflective measurement model of FLE co-creation. More specifically, for SmartPLS3 the parameter value $\mathrm{H}_{0}: \tau=0$ is in the Bonferroni-adjusted confidence interval. In this regard, the Confirmatory Tetrad Analysis (CTA) in PLS does not reject $\mathrm{H}_{0}$ and, therefore, there is evidence for the reflective measurement model specification for FLE co-creation (Table 3) (Coltman et al. 2008; Gudergan et al. 2008; Wilden et al. 2013). The result of this test as a whole, together with theoretical and empirical considerations of Bollen and Ting (1993), Coltman et al. (2008), Glymour et al. (2004), Gudergan et al. (2008), and Wilden et al. (2013), suggests that FLE co-creation is better measured reflectively.

\section{Structural model}

Having successfully tested the measurement models, we proceeded to evaluate the structural model (Chin 1998). Table 4 presents (1) the path coefficients, along with the value of the $t$ statistic, (2) the coefficient of determination $\left(\mathrm{R}^{2}\right)$ (Falk and Miller 1992), and (3) the Stone-Geisser criterion $\left(Q^{2}\right)$ (Geisser 1975; Stone 1974). Also, because we are working with a small sample (101 cases), a post-hoc power analysis was performed (Carbonell et al. 2009; Marcoulides and Saunders 2006). This power analysis was carried out with the statistical package $\mathrm{G}^{+}$ Power 3 (Faul et al. 2007), which allowed us to determine that for the structural model and the sample we work, the power value is 0.85 ( $\alpha=0.05$ and $\mathrm{f} 2=0.15)$, which exceeds the criterion of 0.80 recommended by Cohen (1988). The $t$-statistic was calculated using a bootstrap method that analyzes the level of significance of the path coefficients (Henseler et al. 2009). We also employed the Falk and Miller (1992) criteria, so that the $\mathrm{R}^{2}$ for each of the latent dependent variables is not below 0.10 .

Table 4 shows that the $\mathrm{R}^{2}$ values for FLE outcomes $\left(\mathrm{R}^{2}=\right.$ $0.132)$, customer outcomes $\left(R^{2}=0.406\right)$, NSD speed $\left(R^{2}=\right.$ $0.126)$, NS quality $\left(\mathrm{R}^{2}=0.485\right)$, and NS market performance $\left(\mathrm{R}^{2}=0.282\right)$ exceed the critical level stated above. Working with similar $\mathrm{R}^{2}$ values can be found in the literature (Carbonell 
et al. 2009). We also analyzed $Q^{2}$ values, which vary between 0.055 and 0.264 (Table 4), suggesting acceptable levels of predictive relevance (Chin and Newsted 1999). Furthermore, a global criterion of goodness-of-fit (GoF) for structural equation models in PLS (Tenenhaus et al. 2005, p. 173), defined "as the geometric mean of the average communality and the average $\mathrm{R}^{2}$,"should also be computed. For the complete model (Table 2), a GoF value of 0.480 was obtained, which allows us to conclude that the model performs well (Wetzels et al. 2009).

When analyzing the hypothesized relationships in the proposed model (Tables 4 and 5), the results provided no support for the first hypothesis (H1) because the effect of FLE cocreation on NS market performance is non-significant (path coefficient $=0.063 ; t$-statistic $=0.736$ ). In order to better understand this result, we analyzed the indirect effects of FLE cocreation on NS market performance following the resources route and the operational route.

With reference to the resources route (H2-H5) (Table 4), results show that the influence of FLE co-creation on FLE outcomes is significant (H2: path coefficient $=0.181 ; t$-statistic $=2.074 ; p<0.05)$. However, in analyzing the effect of FLE co-creation on customer outcomes, the expected causal relationship was not significant (H3: path coefficient $=0.079$; $t$ statistic $=1.027)$. This was so even though the literature states that FLE co-creation allows incorporating into the NSDP valuable market information, which has a positive effect on the service innovation performance among customers (Cadwallader et al. 2010; Korhonen and Kaarela 2011). In the resources route, $\mathrm{H} 4$ was confirmed; thus, FLE outcomes positively influence customer outcomes (path coefficient $=$ $0.402 ; t$-statistic $=4.355 ; p<0.01)$. The final effect hypothesized within the resources route, the direct impact of customer outcomes on NS market performance (H5) was also supported (path coefficient $=0.302 ; t$-statistic $=2.297 ; p<0.05$ ).

In testing the mediating effects hypothesized for the resources route (Table 5), we followed Preacher and Hayes (2008) and Hayes et al. (2011) and bootstrapped the sampling distribution of the indirect effect (Hair et al. 2014). We found that the influence of FLE co-creation on NS market performance is not double-mediated by FLE outcomes and customer outcomes (H10), being the indirect effect for this double mediation $0.022(0.181 \times 0.402 \times 0.302)$, and the $t$-statistic associated being statistically non-significant. Furthermore, within this route two additional simple mediating effects were also assessed. On the one hand, we find that the indirect effect on the relationship FLE co-creation $\rightarrow$ FLE outcomes $\rightarrow$ NS customer outcomes is $0.073(0.181 \times 0.402)$, and that the associated test statistic is statistically significant $(2.147 ; p<0.05)(\mathrm{H} 10 \mathrm{a})$. On the other hand, results indicate that the indirect effect on the relationship FLE outcomes $\rightarrow$ customer outcomes $\rightarrow$ NS market performance is $0.121(0.402 \times 0.302)$, and the associated test statistic is also statistically significant $(1.983 ; p<0.05)(\mathrm{H} 10 \mathrm{~b})$. Therefore, this study confirms that FLE outcomes as well as customer 
Table 4 Structural model results

\begin{tabular}{|c|c|c|}
\hline Paths specified & Standardized coefficients & $t$-value bootstrap ${ }^{\mathrm{a}}$ \\
\hline \multicolumn{3}{|l|}{ Control relationships } \\
\hline Type of customer $\rightarrow$ FLE outcomes & 0.179 & $1.694^{*}$ \\
\hline Type of customer $\rightarrow$ Customer outcomes & 0.099 & $1.194^{\mathrm{n} . \mathrm{s}}$ \\
\hline Type of customer $\rightarrow$ NS market performance & -0.165 & $1.719^{*}$ \\
\hline Type of customer $\rightarrow$ NSD speed & 0.070 & $0.663^{\text {n.s. }}$ \\
\hline Type of customer $\rightarrow$ NS quality & 0.059 & $0.736^{\text {n.s. }}$ \\
\hline NS Synergy $\rightarrow$ FLE outcomes & 0.234 & $2.000^{* *}$ \\
\hline NS Synergy $\rightarrow$ Customer outcomes & 0.344 & $3.069^{* *}$ \\
\hline NS Synergy $\rightarrow$ NS market performance & -0.105 & $0.726^{\text {n.s. }}$ \\
\hline NS Synergy $\rightarrow$ NSD speed & 0.239 & $2.231^{* *}$ \\
\hline NS Synergy $\rightarrow$ NS quality & 0.293 & $3.612^{* * *}$ \\
\hline \multicolumn{3}{|l|}{ Model relationships } \\
\hline H1: FLE co-creation $\rightarrow$ NS market performance & 0.063 & $0.736^{\text {n.s. }}$ \\
\hline H2: FLE co-creation $\rightarrow$ FLE outcomes & 0.181 & $2.074^{* *}$ \\
\hline H3: FLE co-creation $\rightarrow$ Customer outcomes & 0.079 & $1.027^{\text {n.s. }}$ \\
\hline H4: FLE outcomes $\rightarrow$ Customer outcomes & 0.402 & $4.355^{* * *}$ \\
\hline H5: Customer outcomes $\rightarrow$ NS market performance & 0.302 & $2.297^{* *}$ \\
\hline H6: FLE co-creation $\rightarrow$ NSD speed & 0.221 & $2.500^{* *}$ \\
\hline H7: FLE co-creation $\rightarrow$ NS quality & 0.023 & $0.298^{\text {n.s. }}$ \\
\hline H8: NSD speed $\rightarrow$ NS quality & 0.543 & $8.309^{* * *}$ \\
\hline H9: NS quality $\rightarrow$ NS market performance & 0.348 & $3.144^{* * *}$ \\
\hline Latent variable & $\mathrm{R}^{2}$ & $Q^{2}$ \\
\hline FLE outcomes & 0.132 & 0.085 \\
\hline Customer outcomes & 0.406 & 0.264 \\
\hline NSD speed & 0.126 & 0.055 \\
\hline NS quality & 0.485 & 0.256 \\
\hline NS market performance & 0.282 & 0.238 \\
\hline
\end{tabular}

n.s. non-significant

${ }^{* * * *} p<0.01 ;{ }^{* *} p<0.05 ;{ }^{*} p<0.10$

${ }^{\text {a }}$ The $t$-value bootstrap is computed using 500 subsamples (Henseler et al. 2009)

outcomes act as full mediators in each of the aforementioned simple mediating relationships ( $\mathrm{H} 10 \mathrm{a}$ and $\mathrm{H} 10 \mathrm{~b}$ ).

Regarding the operational route (H6-H9) (Table 4), we confirmed that FLE co-creation has a positive and significant effect on NSD speed (H6: path coefficient $=0.221$; $t$-statistic $=$ 2.500; $p<0.05)$. We did not confirm the seventh hypothesis, $\mathrm{H} 7$, which states that FLE co-creation influences NS quality directly and positively (path coefficient $=0.023 ; t$-statistic $=$ 0.298 ). Examining the consequences of NSD speed, we found that this variable positively affects NS quality (H8: path coefficient $=0.543 ; t$-statistic $=8.309 ; p<0.01){ }^{4}$ For the final hypothesized relationship of the operational route, H9, we

\footnotetext{
${ }^{4}$ Responding to a suggestion from one of the reviewers, we also tested whether NSD speed had a curvilinear effect on NS quality within the proposed structural model. The empirical results do not confirm this curvilinear relationship (path coefficient $=-0.035$; $t$-statistic $=0.877$ ).
}

corroborated that NS quality positively impacts NS market performance (path coefficient $=0.348 ; t$-statistic $=3.144$; $p<0.01)$.

For testing the mediating effects hypothesized in the operational route (Table 5), we again employed procedures from Preacher and Hayes (2008) and Hayes et al. (2011), and bootstrapped the sampling distribution of the indirect effect (Hair et al. 2014). We confirmed that the impact of FLE cocreation on NS market performance is double-mediated by NSD speed and NS quality, being the indirect effect for this double mediation $0.042(0.221 \times 0.543 \times 0.348)$, and the associated $t$-statistic being statistically significant $(1.826 ; p<0.10)$. Two remaining simple mediating effects within the operational route were tested. The first simple mediating effect deals with the indirect effect on the relationship FLE co-creation $\rightarrow$ NSD speed $\rightarrow$ NS quality, which is $0.120(0.221 \times 0.543)$, and the associated test statistic is statistically significant $(2.400$; 
Table 5 Routes' direct, indirect, and total effects

\begin{tabular}{|c|c|c|c|c|}
\hline & $\begin{array}{l}\text { Direct effects } \\
(t \text {-value bootstrap) }\end{array}$ & $\begin{array}{l}\text { Indirect } \\
\text { effects (IE) }\end{array}$ & $\begin{array}{l}\text { Indirect effects } \\
\left.(t \text {-value })^{\mathrm{a}}\right)\end{array}$ & Total effects \\
\hline \multicolumn{5}{|l|}{ Resources route: } \\
\hline H10: FLE co-creation $\rightarrow$ NS market performance & $\begin{array}{l}\mathrm{H} 1=0.063 \\
\left(0.736^{\text {n.s. }}\right)\end{array}$ & $\begin{array}{l}\mathrm{H} 2 * \mathrm{H} 4 * \mathrm{H} 5=0.022 \\
\mathrm{H} 3 * \mathrm{H} 5^{\mathrm{b}} \\
\text { Total } \mathrm{IE}=0.022\end{array}$ & $\begin{array}{l}1.375^{\mathrm{n} . \mathrm{s}} \\
-\end{array}$ & n.a. \\
\hline \multicolumn{5}{|l|}{ Simple mediation within the resources route: } \\
\hline $\begin{array}{l}\text { H10a: FLE co-creation } \rightarrow \text { Customer outcomes } \\
\text { Mediator: FLE outcomes }\end{array}$ & $\begin{array}{l}\mathrm{H} 3=0.079 \\
\left(1.027^{\text {n.s. }}\right)\end{array}$ & $\begin{array}{l}\mathrm{H} 2 * \mathrm{H} 4=0.073 \\
\text { Total } \mathrm{IE}=0.073\end{array}$ & $2.147^{* *}$ & 0.073 \\
\hline $\begin{array}{l}\text { H10b: FLE outcomes } \rightarrow \text { NS market performance } \\
\text { Mediator: Customer outcomes }\end{array}$ & - & $\begin{array}{l}\mathrm{H} 4 * \mathrm{H} 5=0.121 \\
\text { Total } \mathrm{IE}=0.121\end{array}$ & $1.983^{* *}$ & 0.121 \\
\hline \multicolumn{5}{|l|}{ Operational route: } \\
\hline H11: FLE co-creation $\rightarrow$ NS market performance & $\begin{array}{l}\mathrm{H} 1=0.063 \\
\left(0.736^{\text {n.s. }}\right)\end{array}$ & $\begin{array}{l}\mathrm{H} 6 * \mathrm{H} 8 * \mathrm{H} 9=0.042 \\
\mathrm{H} 7 * \mathrm{H} 9^{\mathrm{c}} \\
\text { Total IE }=0.042\end{array}$ & $\begin{array}{l}1.826^{*} \\
-\end{array}$ & 0.042 \\
\hline \multicolumn{5}{|l|}{ Simple mediation within the operational route: } \\
\hline $\begin{array}{l}\text { H11a:FLE co-creation } \rightarrow \text { NS quality } \\
\text { Mediator: NSD speed }\end{array}$ & $\begin{array}{l}\mathrm{H} 7=0.023 \\
\left(0.298^{\text {n.s. }}\right)\end{array}$ & $\begin{array}{l}\mathrm{H} 6 * \mathrm{H} 8=0.120 \\
\text { Total IE }=0.120\end{array}$ & $2.400^{* *}$ & 0.120 \\
\hline $\begin{array}{l}\text { H11b:NSD speed } \rightarrow \text { NS market performance } \\
\text { Mediator: NS quality }\end{array}$ & - & $\begin{array}{l}\mathrm{H} 8 * \mathrm{H} 9=0.189 \\
\text { Total } \mathrm{IE}=0.189\end{array}$ & $2.908 * * *$ & 0.189 \\
\hline
\end{tabular}

n.s. non-significant, $n . a$. not available as no significant effect is computed

*** $p<0.01$; ** $p<0.05 ;{ }^{*} p<0.10$

${ }^{\text {a }}$ In the elaboration of the empirical $t$-value of the indirect effect is divided the original value of the indirect effect by the bootstrapping standard error (Hair et al. 2014). This implied following Preacher and Hayes (2008) and Hayes et al. (2011), and bootstrap the sampling distribution of the indirect effect (Hair et al. 2014)

${ }^{\mathrm{b}}$ This indirect effect could not be computed as $\mathrm{H} 3$ has a non-significant effect

${ }^{\mathrm{c}}$ This indirect effect could not be computed as $\mathrm{H} 7$ has a non-significant effect

$p<0.05$ ) (H11a). The second simple mediating effect refers to the indirect effect on the relationship NSD speed $\rightarrow$ NS quality $\rightarrow$ NS market performance, which is $0.189(0.543 \times 0.348)$, and the test statistic is statistically significant $(2.908 ; p<0.01)$ (H11b). Hence, we observe that NSD speed and NS quality act as full mediators in each of the simple mediating relationships mentioned above (H11a and H11b).

\section{Conclusions}

This study contributes to the service innovation and S-DL literatures by empirically demonstrating that FLE co-creation, understood as NS development with the collaboration of FLEs across all the stages of the innovation process, contributes to service innovation performance from an internal and external perspective. Our model expands prior research, as it reinforces FLEs' role as a key knowledge interface along the NSDP, provides a detailed description of how FLE co-creation affects different performance measures not previously considered in the same study, and allows understanding of how FLE co-creation effects interrelate and move on, following two different routes.

Thus, the service innovation literature acknowledges the potential benefits of FLEs' active participation in the NSDP, in order to take advantage of their knowledge and abilities and to improve NS outcomes. Similarly, the principles of the S-DL underscore the need for effective knowledge transfer mechanisms to allow for operant resource integration in service innovation, which reinforces the need for FLEs' collaboration in the creation of NS offerings, that is, in the design of the valuein-use experienced by customers. However, recent research also recognizes the inherent difficulties in achieving effective co-creation with FLEs during innovation processes (Cadwallader et al. 2010) and acknowledges the scant number of studies on this subject (Melton and Hartline 2010; Østergaarda et al. 2011; Umashankar et al. 2011). Our research contributes to this gap by exploring the various outcomes of FLE co-creation in a business setting (Ostrom et al. 2011). We next discuss the key implications of this research.

\section{Theoretical implications}

Prior research findings show that FLEs' involvement in the NSDP has a positive impact on NSD sales and process efficiency outcomes (Melton and Hartline 2010, 2013), on service innovation volume and radicalness (Ordanini and Parasuraman 2011) and, in the case of internal service innovations (referring to changes in practices that help customer service agents deliver 
customer service), on the magnitude of benefits of the innovation to customer service agents themselves (Umashankar et al. 2011).

In this study, FLE co-creation is analyzed over six stages of the NSDP, and it is made operational in the conceptual model as a second-order reflective construct. Thus, a basic premise of this research, departing from the S-DL view of FLEs as operant resources, is that FLE co-creation involves FLEs' collaboration in all stages of NSDP. Our research offers strong evidence supporting this conceptualization, and confirms the view that FLE co-creation exerts a positive and direct effect on FLE outcomes, which mediate the FLE co-creation-customer outcomes relationship, as well as on NSD speed, which mediates the effect of FLE co-creation on NS quality. Customer outcomes and NS quality benefit NS market performance, although results do not confirm the direct effect of FLE cocreation on the latter variable. This finding highlights the importance of the mediating role exerted by the performance outcomes integrated into the resources and operational routes.

Thus, results indicate that FLEs' engagement in the NSDP increases contact employees' satisfaction and stimulus, fosters their creativity and commitment to the organization, and improves their contribution to the firm's common knowledge (FLE outcomes). Hence, this research is in line with the literature suggesting that FLE co-creation has strong motivating effects, as it improves the employees' alignment with the organization's objectives (Kesting and Ulhøi 2010) and enhances FLE satisfaction (Cadwallader et al. 2010). In this way, FLE co-creation might also contribute to FLEs' job satisfaction, preventing job burnout (Singh 2000) and favoring FLEs' better shape to contribute to future service innovations, although these aspects deserve further investigation. In this respect, Lages and Piercy (2012) demonstrate that FLEs' job satisfaction and affective organizational commitment constitute key drivers of the generation of ideas for service improvement. However, according to the former reasoning, job satisfaction could also be a consequence of FLE co-creation.

Moreover, FLE outcomes mediate the impact of FLE cocreation on customer outcomes. FLE co-creation involves these employees' empowerment and recognition and, therefore, an organizational climate that triggers FLEs' satisfaction and commitment, which in turn leads to greater customer benefits from the NS. Therefore, FLE co-creation improves customer outcomes through FLE outcomes, although our empirical findings do not support the direct relationship between FLE co-creation and customer outcomes. Nevertheless, from an SDL perspective, these results do not contradict the value of FLEs as key operant resources that enable firms to define new and attractive service innovations (Edvardsson et al. 2012; Vargo and Lusch 2008). FLEs' input in the NSDP allows incorporating the latest market requirements as well as refining the service offering in the light of former service failures. FLE co-creation also allows anticipating the FLEs' training needs to maximize the customer's utility and avoid potential problems during the NS provision. In this way, FLEs' knowledge and skills become highly valuable to satisfy customers' demands, prevent service failure, and improve FLEs' training to provide the NS. All these effects reinforce FLE outcomes and, in this way, allow enhancing the customers' service experience. Therefore, in line with prior research (Cadwallader et al. 2010; Zeithaml et al. 2009), current findings underpin the critical role of FLEs in service contexts for NS implementation and success among customers. Customer outcomes prove to foster improved NS market performance, confirming prior research findings that link customer's satisfaction, sales, and profits in the service context. Customer outcomes also mediate the relationship between FLE outcomes and the NS market performance. Accordingly, the resources route reveals a chain of effects that take place from FLE co-creation to NS market performance and that supports the connection between employees' and customers' constructs contended by the Service-Profit Chain model (Heskett et al. 1994).

However, contrary to our expectations, the influence of FLE co-creation on NS market performance is not doublemediated by FLE outcomes and customer outcomes. Thus, following the resources route, the significant effect of FLE co-creation concludes in the customer outcomes and does not achieve NS market performance. Recent research (Kim 2014) analyzes the Service-Profit Chain model, confirming the positive connection of effects from a positive and motivating working environment to customers' satisfaction and loyalty. However, to the extent of our knowledge, the significance of the multiple mediating effects that occur from the firm's internal climate to the service market performance has not been previously tested. Undoubtedly, this issue deserves future research under the perspective of the Service-Profit Chain Model assessing also the "over time" implications of the relationships analyzed.

The research results confirm the beneficial effects of FLE cocreation from an operational perspective. Thus, as expected, FLE co-creation enables a more accurate responsiveness to market needs, avoiding delays and improving NSD speed. These findings are in line with studies that contend the positive effects of FLE co-creation on NS adoption by FLEs and their willingness to recommend the NS, which speeds the NS launch and reduces the time to market. In this way, FLEs prove to be a valuable knowledge interface to allow firms to keep pace with the rapid market evolution and to facilitate NS commercialization.

However, FLE co-creation does not exert a direct significant impact on NS quality. This effect is significantly mediated by NSD speed, which means that customers' perception of superior NS performance in business markets is conditioned by the degree to which firms rapidly provide service innovations that incorporate the latest market trends and latent needs. This evidence contributes to prior research that has demonstrated conflicting results regarding the NSD speed-NS quality relationship. Thus, in line with the findings of Stanko et al. 
(2012), our results indicate that NSD speed allows the ready incorporation of market information and customer feedback to develop service innovations with differentiating characteristics that customers value more highly. Contrary to prior research (Lukas and Menon 2004), no evidence of curvilinear effects is detected in this relationship and, therefore, this result challenges the existence of trade-offs between speed to market and quality (Chen et al. 2005).

Similar to previous research in the service innovation literature, this study also confirms that NS quality has positive impact on NS market performance relative to competition. NS quality also mediates the impact of NSD speed on NS market performance, as determined in prior studies (Stanko et al. 2012). Therefore, within the operational route the two simple mediating effects hypothesized, exerted by NSD speed and NS quality, are positively tested.

Empirical evidence confirms that the impact of FLE cocreation on NS market performance is double-mediated by NSD speed and NS quality. Consequently, the chain of effects derived from FLE co-creation proves to move on across the operational route to reach NS market performance. In this regard, the chain of effects in the resources route ultimately benefits the NS customer outcomes, although it does not significantly reach NS market performance. On the contrary, the operational route is the most effective path to impact NS market performance, which reinforces the view of NSD speed and NS quality as key forerunners of NS success, and which allows us to conclude that the stronger effects of FLE co-creation occur in the operational outcomes of service innovation.

\section{Managerial implications}

Service innovation yields service firm benefits that range from greater sales, expanded market share, and enhanced profits (Melton and Hartline 2010, 2013) to the improvement of firms' operations efficiency, cost reductions, or the internal reinforcement of the corporate image, in this way bolstering staff morale and enhancing the overall organizational fitness (Fitzsimmons and Fitzsimmons 2000; Sanchez-Hernández and Miranda 2011). Therefore, service innovation constitutes a primary driver of market and organic growth for service firms (Melton and Hartline 2010; Ordanini and Parasuraman 2011).

From this perspective, our study offers useful insights and recommendations for business services managers, particularly in the KIBS sector. First, this study confirms that FLEs constitute valuable intellectual assets for guiding service innovation from the NS idea generation to market launch in business services markets. Therefore, service managers that seek to be best positioned for innovation need to bear in mind that: (1) all employees are potentially creative individuals, who may have in-depth and highly context-dependent operational knowledge, as well as relevant network contacts outside the organization which can also be an important source of ideas (Kesting and Ulhøi 2010), and (2) innovation can no longer be conceived of as a primarily management driven activity. Accordingly, service executives have to develop an adequate innovative culture that values the potential of their FLEs to make the NS more marketable and obtain optimal operational results; a culture that empowers FLEs to actively collaborate in all the NSDP stages in order to create successful service innovations from the customers and market viewpoint.

Second, in addition to the existence of an adequate organizational culture, supportive of employees' contribution to service innovation and tolerant of failure, FLE co-creation needs time, resources, incentives, and management assistance to really occur. Thus, FLEs' contribution to the NSDP may suffer from shortcomings for a number of reasons, such as ideas that do not fit into the firm's global strategy, or even internal conflicts among managers and employees regarding their respective status in the organization (Kesting and Ulhøi 2010). Therefore, service managers have to promote flattened structures for innovation that integrate managers and FLEs to collaborate and share strategic objectives, as well as put in place the right support systems and processes to achieve these goals. This involves that service managers have to "develop effective ways of capturing, sharing, and acting upon FLEs insights about customer preferences and service delivery process refinements" (Melton and Hartline 2013, p. 78).

In this respect, "Employees First, Customers Second" (EFCS) has become the determining philosophy for HCL Technologies in transferring the responsibility for change and value proposal to FLEs, as well as for growing trust and transparency between managers and employees. Among the support systems that manifest this culture of innovation at HCL is the "Value Portal," an employee idea exchange platform intended to channel the innovative energy of grassrootslevel employees to collaborate, innovate, and facilitate the implementation of their ideas to the customers. The Value Portal also serves as the interface where HCL employees can share knowledge, ideas and solutions with employees of customer firms and thus define more accurate value proposals from the customer firms' viewpoint (Ramdas and Gajulapalli 2008). In this way, the case of HCL Technologies also illustrates how service innovation is driven by multiple stakeholders (employees and customers) in the KIBS sector.

Finally, based on this study's findings, service managers can learn how foster speed to market and NS quality in order to compete in complex and rapid evolving contexts, such as KIBS markets. Our results confirm that FLE co-creation exerts an indirect effect on NS quality through NSD speed, which benefits directly from FLE co-creation. NS synergy with the firm's resources, although initially introduced in the study as a control variable, also proves to improve NSD speed and NS quality. Therefore, this study reinforces that service innovations that exploit the firm's strengths and marketing capabilities achieve better operational outcomes. NSD speed and NS quality lead to 
an improved NS market performance and, therefore, service managers must be aware of the need to rapidly incorporate the market needs into valuable service offerings from the customer's viewpoint, and acknowledge the role of FLEs in this process. Similarly, our results reveal that by exploiting FLEs knowledge during the NSDP service managers can also reinforce FLEs' satisfaction and commitment to the organization, which ultimately leads to improved customer outcomes and NS market performance. Thus, from an S-DL perspective, knowledge is the very essence for service provision; FLEs are operant resources that gather useful knowledge to produce service innovations and, moreover, FLEs' collaboration in this process improves NS performance. Accordingly, managers must approach the NSDP as a key interface for FLEs' knowledge transfer and, in doing so, contributing to NS success.

\section{Limitations and further research}

This study has a number of limitations that need to be considered in any generalization of its findings. First, the study uses cross-sectional data. This approach makes it difficult to be sure that the causal relationships and the mediating effects of the existing model will not change over time. A longitudinal study would overcome this limitation and further strengthen the results.

Second, the constructs were measured from subjective perceptions of a single informant in each firm, which constitutes a potential source of common method bias. However, using multiple informants might reduce response rates (Kim and Cavusgil 2009), and prior research confirms a strong correlation between the data provided by different informants in the same organization (Homburg et al. 2002). The good results from the Harman's single-factor test and the marker variable technique, as well as the adequate fit of the model analyzed (Joshi 2010), also support that common method bias has not a significant role in this study. Nevertheless, although the KIBS managers in this study proved to be fully knowledgeable of FLE outcomes and customer outcomes achieved by the NS, researchers might consider measuring these variables as perceived by customers and FLEs (Ordanini and Parasuraman 2011).

Third, the study uses subjective measures of NS performance. This is common practice in the literature due to firms' resistance to providing quantitative data about their sales, profits, and market share; however, future studies would benefit from consideration of objective measures of NS performance and differentiation between short-term and long-term NS performance indicators (Stanko et al. 2012).

Fourth, the conceptual model was tested using a sample of 101 business firms, which calls for confirmation of the results through larger studies and in different market settings. The 101-firm subsample considered in this study is similar in observable characteristics to the 246 respondents of the overall research; nevertheless, non-response can lead to sample selection bias if a systematic and unobservable difference exists between respondents and non-respondents (Whitehead et al. 1993). In this respect, the study does not take into account qualitative measures that may establish differences between the subsample considered and the global sample.

Future research directions include determining the organizational antecedents to FLE co-creation. In this regard, we believe that market orientation, internal marketing, and top management support are variables to be considered in future conceptual models. Another aspect that merits further examination is the relative contribution of innovation co-creation with different actors to NS success in business markets, considering the NS performance measures used in this study or other variables such as innovation volume and radicalness (Ordanini and Parasuraman 2011). The study of the individual effects of FLEs' collaboration in each of the NSD stages can also enrich understanding of how the benefits of FLE cocreation are generated. Finally, the analysis of the potential negative effects of FLE co-creation in terms of perceived workload or organizational conflict also deserve the attention of future research efforts. We need to understand to a greater extent which variables are the key drivers and which costs are the greatest inhibitors of FLE co-creation.

Acknowledgments The authors wish to thank the Spanish Ministry of Economy and Competitiveness for the financial support provided for this research under the 2012 Call for R\&D Projects (Project reference number: ECO2012-31300). The authors also gratefully acknowledge the valuable and constructive comments from the anonymous reviewers and the editor, which helped to strengthen the paper. This gratitude also extends to the helpful guidance, comments and suggestions from Heiner Evanschitzky, Ad de Jong, and David W. Stewart. All remaining errors are our own.

\section{Appendix: Measurement scales}

\section{Frontline employee co-creation (FLE_C)}

\begin{tabular}{|c|c|c|c|c|c|c|}
\hline $\begin{array}{l}\text { Ways to } \\
\text { achieve } \\
\text { FLEs' } \\
\text { collaboration } \\
\text { in the NSDP } \\
\text { stages: }\end{array}$ & $\begin{array}{l}\text { Idea } \\
\text { generation }\end{array}$ & $\begin{array}{l}\text { Idea } \\
\text { selection }\end{array}$ & $\begin{array}{r}\text { Business } \\
\text { analysis }\end{array}$ & $\begin{array}{l}\text { Service and } \\
\text { process } \\
\text { development }\end{array}$ & $\begin{array}{l}\text { Market } \\
\text { test } \\
\text { t }\end{array}$ & $\begin{array}{r}\text { Market } \\
\text { launch }\end{array}$ \\
\hline $\begin{array}{l}\text { 1. Frequent } \\
\text { meetings }\end{array}$ & IG1 & IS1 & BA1 & S\&PD1 & MKT1 & MKL1 \\
\hline $\begin{array}{l}\text { 2. Active } \\
\text { participation } \\
\text { in the } \\
\text { development } \\
\text { team }\end{array}$ & IG2 & IS2 & BA2 & S\&PD2 & MKT2 & MKL2 \\
\hline $\begin{array}{l}\text { 3. Detailed } \\
\text { consultations }\end{array}$ & IG3 & IS3 & BA3 & S\&PD3 & MKT3 & MKL3 \\
\hline
\end{tabular}


1. Frequent meetings, e.g., "FLEs collaborated in the 'NSDP stage' (e.g., idea generation) holding frequent meetings with the organization's internal team in charge of the NS development"

2. Active participation in the development team, e.g., "FLEs collaborated in the 'NSDP stage' (e.g., idea generation) participating actively in the internal $\mathrm{R} \& \mathrm{D} /$ development team tasks"

3. Detailed consultations, e.g., "FLEs collaborated in the 'NSDP stage' (e.g., idea generation) throughout detailed consultations with the internal R\&D/development team"

\section{Frontline employee outcomes (FLEO)}

FLEO1 $=$ The NS has improved FLEs' satisfaction.

FLEO2 $=$ The NS has served as a stimulus to the FLEs.

FLEO3 = The NS has fostered FLEs' creativity and commitment to the organization.

FLEO4=The NS has fostered FLEs' development of the firm's common knowledge.

\section{Customer outcomes (CO)}

$\mathrm{CO} 1=$ The NS has allowed us to improve the loyalty and satisfaction of our customers.

$\mathrm{CO} 2=$ The NS has improved the firm's commercial image.

$\mathrm{CO} 3=$ The NS helped to reinforce the firm's competitive leadership in the market.

\section{New service development speed (NSD_S)}

NSD_S1 $=$ The NS was developed before other competitive alternatives.

NSD S2 = We were able to successfully carry out the NSDP in an agile and fast manner.

NSD_S3 $=$ The NS was launched ahead of schedule.

\section{New service quality (NS_Q)}

NS_Q1 = The operation of the NS generates hardly any incidents (complaints, claims, ...).

NS_Q2 = The quality of the NS, in the way it is provided, is greater than the competition's.

NS_Q3 = The NS is designed to deliver greater customer value than competitive alternatives.

\section{New service market performance (NS_MP)}

NS_MP1 $=$ The NS has exceeded market share goals.

NS_MP2 $=$ The NS has exceeded the success targets set by the firm.

NS_MP3 $=$ The NS has exceeded sales targets.
NS_MP4 $=$ The NS has exceeded financial performance targets.

\section{Type of customer (TC)}

$\mathrm{TC} 1=$ Customers that usually benefit first from new market solutions.

TC2 $=$ Customers willing to quickly adopt service innovations.

\section{New service synergy with the firm's resources (NS_SY)}

NS_SY1 = The firm's current capabilities and skills were crucial in determining the decision to develop or not the NS. NS_SY2 = The NS was developed due to its complementarity with the marketing resources of the firm.

\section{References}

Alam, I. (2002). An exploratory investigation of user involvement in new service development. Journal of the Academy of Marketing Science, $30(3), 250-261$.

Alam, I. (2006). Service innovation strategy process: a cross-national comparative analysis. International Marketing Review, 23(3), 234 254.

Alam, I. (2012). New service development in India's business-to-business financial services sector. Journal of Business and Industrial Marketing, 27(3), 228-241.

Anderson, J. C., \& Gerbing, D. W. (1988). Structural equation modelling in practice: a review, recommended two-step approach. Psychological Bulletin, 103(3), 411-423.

Aragón-Correa, J. A., García-Morales, V. J., \& Cordón-Pozo, E. (2007). Leadership, organizational's learning role on innovation, performance: lessons from Spain. Industrial Marketing Management, 36(3), 349-359.

Armstrong, J. S., \& Overton, T. S. (1977). Estimating no response bias in mail surveys. Journal of Marketing Research, 14(3), 396-402.

Arnold, T. J., Fang, E., \& Palmatier, R. W. (2011). The effects of customer acquisition and retention orientations on a firm's radical and incremental innovation performance. Journal of the Academy of Marketing Science, 39(2), 234-251.

Atuahene-Gima, K. (1996). Differential potency of factors affecting innovation performance in manufacturing and services firms in Australia. Journal of Product Innovation Management, 13(1), 35-52.

Atuahene-Gima, K. (2003). The effects of centrifugal and centripetal forces on product development speed and quality: How does problem solving matter? Academy of Management Journal, 46(3), 359-373.

Avlonitis, G. J., Papastathopoulou, P. G., \& Gounaris, S. P. (2001). An empirically-based typology of product innovativeness for new financial services: Success and failure scenarios. Journal of Product Innovation Management, 18(5), 324-342.

Bagozzi, R. P., \& Yi, Y. (1988). On the evaluation of structural equation models. Journal of the Academy of Marketing Science, 16(1), 74-94.

Barroso, C., Cepeda, G., \& Roldán, J. L. (2010). Applying maximum likelihood, PLS on different sample sizes: studies on SERVQUAL model and employee behavior model. In V. E. Vinzi, W. W. Chin, J. Henseler, \& H. Wang (Eds.), Handbook of partial least squares. Concepts, methods and applications. Berlin: Springer. 
Bateson, J. (2002). Consumer performance and quality in services. Managing Service Quality, 12(4), 206-209.

Bell, S. J., \& Menguc, B. (2002). The employee-organization relationship, organizational citizenship behaviors and superior service quality. Journal of Retailing, 78(2), 131-146.

Bernhardt, K. L., Donthu, N., \& Kennett, P. A. (2000). A longitudinal analysis of satisfaction and profitability. Journal of Business Research, 47(2), 161-171.

Bollen, K. A., \& Ting, K. (1993). Confirmatory tetrad analysis. In P. Marsden (Ed.), Sociological methodology (Vol. 23, pp. 147-175). Cambridge: Blackwell.

Cadwallader, S., Burke, C., Bitner, M., \& Ostrom, A. L. (2010). Frontline employee motivation to participate in service innovation implementation. Journal of the Academy of Marketing Science, 38(2), 219-239.

Carbonell, P., \& Rodríguez, A. I. (2006). The impact of market characteristics and innovation speed on perceptions of positional advantage and new product performance. International Journal of Research in Marketing, 23(1), 1-12.

Carbonell, P., \& Rodríguez, A. I. (2010). The effect of market orientation on innovation speed and new product performance. Journal of Business and Industrial Marketing, 25(7), 501-513.

Carbonell, P., Rodríguez, A. I., \& Pujari, D. (2009). Customer involvement in NS development: an examination of antecedents and outcomes. Journal of Product Innovation Management, 26(5), 536-550.

Carbonell, P., Rodríguez, A. I., \& Pujari, D. (2012). Performance effects of involving lead users, close customers in new service development. Journal of Service Marketing, 26(7), 497-509.

Cavusgil, S. T., Calantone, R. J., \& Zhao, Y. (2003). Tacit knowledge transfer and firm innovation capability. Journal of Business \& Industrial Marketing, 18(1), 6-21.

Chen, J., Reilly, R. R., \& Lynn, G. S. (2005). The impact of speed-tomarket on new product success: the moderating effects of uncertainty. IEEE Transactions on Engineering Management, 52(2), 199-212.

Chi, C., \& Gursoy, D. (2009). Employee satisfaction, customer satisfaction, and financial performance: an empirical examination. International Journal of Hospitality Management, 28(2), 245-253.

Chin, W. W. (1998). The partial least squares approach to structural equation modeling. In G. H. Marcoulides (Ed.), Modern methods for business research. Mahwah: Lawrence Erlbaum Associates.

Chin, W. W., \& Newsted, P. R. (1999). Structural equation modeling analysis with small samples using partial least squares. In R. H. Hoyle (Ed.), Statistical strategies for small sample research. Thousand Oaks: Sage Publications.

Clark, R. A., Hartline, M. D., \& Jones, K. C. (2009). The effects of leadership style on hotel employees' commitment to service quality. Cornell Hospitality Quarterly, 5(2), 209-231.

Cohen, J. (1988). Statistical power analysis for the behavioral science. Hillsdale: Lawrence Erlbaum Associates.

Coltman, T. R., Devinney, T. M., Midgley, D. F., \& Venaik, S. (2008). Formative versus reflective measurement models: two applications of formative measurement. Journal of Business Research, 61(12), $1250-1262$

Cooper, R. G., \& de Brentani, U. (1991). New industrial financial services: what distinguishes the winners. Journal of Product Innovation Management, 8(2), 75-90.

Cooper, R. G., Easingwood, C. J., Edgett, S., Kleinschmidt, E. J., \& Storey, C. (1994). What distinguishes the top performing new products in financial services. Journal of Product Innovation Management, 11(4), 281-299.

Corrocher, N., Cusmano, L., \& Morrison, A. (2009). Modes of innovation in knowledge-intensive business services evidence from Lombardy. Journal of Evolutionary Economics, 19(2), 173-196.

Crosby, L. A., Evans, K. R., \& Cowles, D. (1990). Relationship quality in services selling: an interpersonal influence perspective. Journal of Marketing, 54, 68-81.
Cuddeback, G., Wilson, E., Orme, J. G., \& Combs-Orme, T. (2004). Detecting and statistically correcting sample selection bias. Journal of Social Service Research, 30(3), 19-33.

De Brentani, U. (1991). Success factors in developing new business services. European Journal of Marketing, 25(2), 33-59.

De Brentani, U. (2001). Innovative versus incremental new business services: different keys for achieving success. Journal of Product Innovation Management, 18(3), 169-187.

De Brentani, U., \& Ragot, E. (1996). Developing new business-tobusiness professional services: what factors impact performance? Industrial Marketing Management, 25(6), 517-530.

Drejer, I. (2004). Identifying innovation in surveys of services: a Schumpeterian perspective. Research Policy, 33(3), 551-562.

Edvardsson, B., Kristensson, P., Magnusson, P., \& Sundström, E. (2012). Customer integration within service development-A review of methods and an analysis of insitu and exsitu contributions. Technovation, 32, 419-429.

EMCC -European Monitoring Centre of Change (2005). The knowledgeintensive business services sector - what future? Retrieved June, 2014 from: http://www.eurofound.europa.eu/emcc/sector futures.htm.

Engen, M., \& Magnusson, P. R. (2015). Exploring the role of frontline employees as innovators. The Service Industries Journal, 35(6), 303-324.

Etgar, M. (2008). A descriptive model of the consumer co-production process. Journal of the Academy of Marketing Science, 36(1), 97-108.

European Commission (2012). Knowledge-intensive (business) services in Europe. Directorate-General for Research, Innovation.

Falk, R. F., \& Miller, B. (1992). A primer for soft modeling. Akron: The University Akron Press.

Faul, F., Erdfelder, E., Lang, A., \& Buchner, A. (2007). G*Power 3: a flexible statistical power analysis program for the social, behavioral, and biomedical sciences. Behavioral Research Methods, 39(2), 175-191.

Fitzsimmons, J. A., \& Fitzsimmons, M. (2000). New service development - Creating memorable experiences. Thousand Oaks: Sage Publications.

Fornell, C., \& Larcker, D. F. (1981). Evaluating structural equation models with unobservable variables and measurement error. Journal of Marketing Research, 18(1), 39-50.

Freel, M. (2006). Patterns of technological innovation in knowledge-intensive business services. Industry and Innovation, 13(3), 335-358.

Gallouj, F., \& Weinstein, O. (1997). Innovation in services. Research Policy, 26, 537-556.

Geisser, S. (1975). The predictive sample reuse method with applications. Journal of the American Statistical Association, 70(350), 320-328.

Glymour, C., Scheines, R., Spirtes, P., \& Ramsey (2004). Tetrad IV. Carnegie Mellon University. http://www.phil.cmu.edu/projects/tetrad.

Grönroos, C., \& Voima, P. (2013). Critical service logic: making sense of value creation and co-creation. Journal of the Academy of Marketing Science, 41(2), 133-150.

Grönross, C. (1982). Strategic management, marketing in the service sector. Helsinki-Helsingfors: Swedish School of Economics.

Gruner, K. E., \& Homburg, C. (2000). Does customer interaction enhance new product success? Journal of Business Research, 49(1), 1-14.

Gudergan, S. P., Ringle, C. M., Wende, S., \& Will, A. (2008). Confirmatory tetrad analysis in PLS path modeling. Journal of Business Research, 61(12), 1238-1249.

Gwinner, K. P., Bitner, M. J., Brown, S. W., \& Kumar, A. (2005). Service customization through employee adaptativeness. Journal of Service Research, 8(2), 131-148.

Hair, J. F., Ringle, C. M., \& Sarstedt, M. (2011). PLS-SEM: indeed a silver bullet. Journal of Marketing Theory and Practice, 19(2), 139-151.

Hair, J. F., Jr., Hult, G. T. M., Ringle, C. M., \& Sarstedt, M. (2014). A primer on partial least squares structural equation modeling (PLSSEM). Thousand Oaks: Sage. 
Hansen, J. M., McDonald, R. E., \& Mitchell, R. K. (2013). Competence resource specialization, causal ambiguity, and the creation of decay of competitiveness: the role of marketing strategy in new product performance and shareholder value. Journal of the Academy of Marketing Science, 41(3), 300-319.

Hayes, A. F., Preaches, K. J., \& Myers, T. A. (2011). Mediation and the estimation of indirect effects in political communication research. In E. P. Bucy \& R. L. Roberts (Eds.), Sourcebook for political communication research: methods, measure, and analytical techniques (pp. 434-465). New York: Routledge.

Hennig-Thurau, T., Groth, M., Paul, M., \& Gremler, D. D. (2006). Are all smiles created equal? How emotional contagion and emotional labor affect service relationships. Journal of Marketing, 70, 58-73.

Henseler, J., Ringle, C., \& Sinkovics, R. R. (2009). The use of partial least squares path modeling in international marketing. In R. E. Sinkovics, P. Ghauri (Eds.), Advances in international marketing. Emerald Group Publishing Limited.

Hertog, P. (2000). Knowledge-intensive business services as coproducers of innovation. International Journal of Innovation Management, 4, 491-528.

Heskett, J. L., Jones, T. O., Loveman, G. W., Sasser, W. E., Jr., \& Schlesinger, L. A. (1994). Putting the service-profit chain to work. Harvard Business Review, 72, 164-174.

Homburg, C., Krohmer, H., Cannon, J. P., \& Kiedaisch, I. (2002). Customer satisfaction in transnational buyer-seller relationships. Journal of International Marketing, 10(4), 1-29.

Hoyer, W., Chandy, R., Dorotic, M., Krafft, M., \& Singh, S. (2010). Consumer cocreation in new product development. Journal of Service Research, 13(3), 283-296.

Hoyt, D., \& Rao, H. (2006). Rite-solutions: Mavericks unleashing the quiet genius of employees. Stanford: Stanford Graduate School of Business Case HR-27.

Hsu, Y.-H., \& Fang, W. (2009). Intellectual capital, new product development performance: the mediating role of organizational learning capability. Technological Forecasting and Social Change, 76, 664-677.

Huang, C. T., \& Tsai, K. H. (2014). Synergy, environmental context, and new product performance: a review based on manufacturing firms. Industrial Marketing Management, 43(8), 1407-1419.

Hulland, J. (1999). Use of partial least squares (PLS) in strategic management research: a review of four recent studies. Strategic Management Journal, 20(2), 195-204.

Hwang, Y., \& Grant, D. (2011). Behavioral aspects of enterprise systems adoption: an empirical study on cultural factors. Computers in Human Behavior, 27(2), 988-996.

Javalgi, R. R. G., Gross, A. C., Joseph, W. B., \& Granot, E. (2011). Assessing competitive advantage of emerging markets in knowledge intensive business services. Journal of Business and Industrial Marketing, 26(3), 171-180.

Jayasimha, K. R., Nargundkar, R., \& Murugaiah, V. (2007). New service development (NSD): role of customer contact executives. Vision: The Journal of Business Perspective, 11(2), 1-6.

Johne, A., \& Storey, C. (1998). New service development: a review of the literature, annotated bibliography. European Journal of Marketing, $32(3 / 4), 184-252$.

Joshi, A. W. (2010). Salesperson influence on product development: insights from a study of small manufacturing organizations. Journal of Marketing, 74(1), 94-107.

Joshi, A., \& Sharma, S. (2004). Customer knowledge development: antecedents, impact on new product performance. Journal of Marketing, 68(3), 47-59.

Kandemir, D., Yaprak, A., \& Cavusgil, S. T. (2006). Alliance orientation: conceptualization, measurement, and impact on market performance. Journal of the Academy of Marketing Science, 34(3), 324-340.

Karpen, I. O., Bove, L. L., \& Lukas, B. A. (2012). Linking servicedominant logic and strategic business practice: a conceptual model of a service-dominant orientation. Journal of Service Research, 15(1), 21-38.

Kessler, E. H., \& Bierly, P. E. (2002). Is faster really better? An empirical test of the implications of innovation speed. IEEE Transactions on Engineering Management, 49(1), 2-12.

Kesting, P., \& Ulhøi, J. P. (2010). Employee-driven innovation: extending the license to foster innovation. Management Decision, 48(1), 65-84.

Kim, D., \& Cavusgil, E. (2009). The impact of supply chain integration on brand equity. Journal of Business and Industrial Marketing, 2(7), 496-505.

Kim, G. J. (2014). Applying Service Profit Chain model to the Korean restaurant industry. International. Journal of Hospitality Management, 36, 1-13.

Korhonen, H. M. E., \& Kaarela, I. (2011). Corporate customers' resistance to industrial service innovations. International Journal of Innovation Management, 15(3), 479-503.

Kuester, S., Schuhmacher, M. C., Gast, B., \& Worgul, A. (2013). Sectorial heterogeneity in new service development: an exploratory study of service types and success factors. Journal of Product Innovation Management, 30(3), 533-544.

Lages, C. R., \& Piercy, N. F. (2012). Key drivers of frontline employee generation of ideas for customer service improvement. Journal of Service Research, 15(2), 215-230.

Landry, R., Amara, N., \& Doloreux, D. (2012). Knowledge-exchange strategies between KIBS firms and their clients. The Service Industries Journal, 32(2), 291-320.

Lin, X., \& Germain, R. (2004). Antecedents to customer involvement in product development: comparing US and Chinese firms. European Management Journal, 22(2), 244-255.

Lindell, M. K., \& Whitney, D. J. (2001). Accounting for common method variance in cross-sectional research designs. Journal of Applied Psychology, 86(1), 114-121.

Lovelock, C., \& Wright, L. (2001). Principles of service marketing and management. Prentice Hall.

Løwendahl, B. (2005). Strategic management of professional service firms. Copenhagen Business School Press DK.

Lukas, B., \& Menon, A. (2004). New product quality: intended, unintended consequences of new product development speed. Journal of Business Research, 57(11), 1258-1264.

Lukas, B. A., Menon, A., \& Bell, S. J. (2002). Organizing for new product development speed and the implications for organizational stress. Industrial Marketing Management, 31(4), 349-355.

Lusch, R. F., Vargo, S. L., \& O’Brien, M. (2007). Competing through service: insights from service-dominant logic. Journal of Retailing, 83(1), 5-18.

Lynn, G. S., Reilly, R. R., \& Akgun, A. E. (2000). Knowledge management in new product teams: practices and outcomes. IEEE Transactions on Engineering Management, 47(2), 221-231.

Magnusson, P. R. (2009). Exploring the contributions of involving ordinary users in ideation of technology-based services. Journal of Product Innovation Management, 26(5), 578-593.

Malhotra, N. K., Sim, S. S., \& Patil, A. (2006). Common method variance in IS research: A comparison of alternative approaches and reanalysis of past research. Management Science, 52(12), 1865-1883.

Marcoulides, G. A., \& Saunders, C. (2006). PLS: a silver bullet? Management Information Systems Quarterly, 30(2), 1.

Marinova, D., Ye, J., \& Singh, J. (2008). Do frontline mechanisms matter? Impact of quality, productivity orientations on unit revenue, efficiency and customer satisfaction. Journal of Marketing, $7(2), 28-45$.

McNally, R. C., Akdeniz, M. B., \& Calantone, R. J. (2011). New product development processes, new product profitability: exploring the mediating role of speed to market and product quality. Journal of Product Innovation Management, 28(S1), 63-77. 
Melancon, J. P., Griffith, D. A., Noble, S. M., \& Chen, Q. (2010). Synergistic effects of operant knowledge resources. Journal of Services Marketing, 24(5), 400-411.

Melton, H. L., \& Hartline, M. D. (2010). Customer and frontline employee influence on new service development performance. Journal of Service Research, 13(4), 411-425.

Melton, H. L., \& Hartline, M. D. (2013). Employee collaboration, learning orientation, and new service development performance. Journal of Service Research, 16(1), 67-81.

Menor, L. J., Tatikonda, M., \& Sampson, S. (2002). New service development: areas for exploitation and exploration. Journal of Operations Management, 20(2), 135-157.

Michel, S., Brown, S. W., \& Gallan, A. S. (2008). An expanded and strategic view of discontinuous innovations: deploying a servicedominant logic. Journal of the Academy of Marketing Science, 36(1), 54-66.

Miles, I. (2005). Knowledge intensive business services: prospects and policies. Foresight, 7(6), 39-63.

Miozzo, M., \& Grimshaw, D. (2005). Modularity and innovation in knowledge-intensive business services: IT outsourcing in Germany and the UK. Research Policy, 34(9), 1419-1439.

Murray, J. Y., Kotabe, M., \& Westjohn, S. A. (2009). Global sourcing strategy, performance of knowledge-intensive business services: a two-stage strategic fit model. Journal of International Marketing, 4, $90-105$.

Nätti, S., \& Ojasalo, J. (2008). What prevents effective utilization of customer knowledge in professional B-to-B services? An empirical study. The Service Industries Journal, 28(9), 1199-1213.

Ngo, L. V., \& O'Cass, A. (2013). Innovation and business success: the mediating role of customer participation. Journal of Business Research, 66(8), 1134-1142.

Nijhof, A., Krabbendam, K., \& Looise, J. C. (2002). Innovation through exemptions: building upon the existing creativity of employees. Technovation, 22, 675-683.

O'Cass, A., \& Weerawardena, J. (2010). The effects of perceived industry competitive intensity, marketing-related capabilities: drivers of superior brand performance. Industrial Marketing Management, 39(4), 571-581.

O'Hern, M. S., \& Rindfleisch, A. (2010). Customer co-creation: a typology, research agenda. Review of Marketing Research, 6, 84-106.

OECD. (2012a). Service $R \& D$, innovation: policy issues paper. Paris: OECD

OECD. (2012b). Policies to promote service $R \& D$ and innovation: an initial inventory. Paris: OECD.

Ordanini, A., \& Parasuraman, A. (2011). Service innovation viewed through a service-dominant logic lens: a conceptual framework, empirical analysis. Journal of Service Research, 14(1), 3-23.

Østergaarda, C. R., Timmermansa, B., \& Kristinssonb, K. (2011). Does a different view create something new? The effect of employee diversity on innovation. Research Policy, 40, 500-509.

Ostrom, A. L., Bitner, M. J., Brown, S. W., Burkhard, K. A., Goul, M., Smith-Daniels, V., Demirkan, H., \& Rabinovich, E. (2011). Moving forward, making a difference: research priorities for the science of service. Journal of Service Research, 13(1), 4-36.

Ottenbacher, M., \& Harrington, R. J. (2008). New service development of entrepreneurial innovations in the IT sector. Entrepreneurship and Innovation, 9(1), 21-31.

Ottenbacher, M., Gnoth, J., \& Jones, P. (2006). Identifying determinants of success in development of new high-contact services. International Journal of Service Industry Management, 17(4), 344-363.

Pavlou, P. A., \& Gefen, D. (2005). Psychological contract violation in online marketplaces: antecedents, consequences, and moderating role. Information Systems Research, 16(4), 372-399.
Pavlou, P. A., Liang, H., \& Xue, Y. (2007). Understanding and mitigating uncertainty in online exchange relationships: a principal-agent perspective. MIS Quarterly, 31(1), 105-136.

Podsakoff, P. M., \& Organ, D. W. (1986). Self-reports in organizational research: problems and prospects. Journal of Management, 12(4), 531-544.

Podsakoff, P. M., Mackenzie, S. B., Lee, J., \& Podsakoff, P. (2003). Common method biases in behavioral research: a critical review of the literature, recommended remedies. Journal of Applied Psychology, 88(5), 879-903.

Podsakoff, P. M., Mackenzie, S. B., \& Podsakoff, N. P. (2012). Sources of method bias in social science research and recommendations on how to control it. Annual Review of Psychology, 63, 539-569.

Prahalad, C. K., \& Krishnan, M. S. (2008). The new age of innovation: driving cocreated value through global networks. New York: McGraw Hill.

Preacher, K. J., \& Hayes, A. F. (2008). Asymptotic and resampling strategies for assessing and comparing indirect effects in multiple mediator models. Behavior Research Methods, 40(3), 879-891.

Ramdas, K., \& Gajulapalli, R. (2008). HCL Technologies: employee first, customer second. Harvard Business Review Case Study.

Reinartz, W., Haenlein, M., \& Henseler, J. (2009). An empirical comparison of the efficacy of covariance-based and variance-based SEM. International Journal of Research in Marketing, 26(4), 332-344.

Ringle, C. M., Wende, S., \& Becker, J. M. (2014). SmartPLS 3. Hamburg: SmartPLS. Retrieved from http://www.smartpls.com

Rubalcaba, L., Gallego, J., Hipp, C., Gallouj, F., Gallouj, C., Savona, M., Djellal, F., \& Fornahl, D. (2008). Towards a European strategy in support of innovation in services. A review of key evidence, policy issues. Brussels: Final Report, INNOVA Innovation Watch, DG Enterprise, Industry.

Sanchez-Hernández, M. I., \& Miranda, F. J. (2011). Linking internal market orientation and new service performance. European Journal of Innovation Management, 14(2), 207-226.

Santamaría, L., Nieto, M. J., \& Miles, I. (2012). Service innovation in manufacturing firms. Technovation, 32(2), 144-155.

Santos-Vijande, M. L., López Sánchez, J. A., \& González Mieres, C. (2012). Organizational learning, innovation and performance in KIBS. Journal of Management \& Organization, 18(6), 870-904.

Santos-Vijande, M. L., Díaz-Martín, A. M., Suárez-Alvarez, L., \& del Río-Lanza, A. B. (2013a). An integrated service recovery system (ISRS) Influence on knowledge-intensive business services performance. European Journal of Marketing, 47(5/6), 934-963.

Santos-Vijande, M. L., González Mieres, C., \& López Sánchez, J. A. (2013b). An assessment of innovativeness in KIBS: implications on KIBS' co-creation culture, innovation capability and performance. Journal of Business \& Industrial Marketing, 28(2), 86-102.

Schneider, B., \& Bowen, D. (1984). New service design, development, implementation, the employee. In W. R. George \& C. E. Marshall (Eds.), Developing new services (pp. 82-101). Chicago: American Marketing Association.

Shearmur, R., \& Doloreux, D. (2013). Innovation, knowledge-intensive business service: the contribution of knowledge-intensive business service to innovation in manufacturing establishments. Economics of Innovation and New Technology, 22(8), 751-774.

Singh, J. (2000). Performance productivity and quality of frontline employees in service organizations. Journal of Marketing, 64(2), 15-34.

Skålén, P., Gummerus, J., von Koskull, C., \& Magnusson, P. R. (2015). Exploring value propositions and service innovation: a servicedominant logic study. Journal of the Academy of Marketing Science, 43(2), 137-148.

Smith, D., \& Mindrum, C. (2008). How to capture the essence of innovation. Accenture Outlook Journal-The Journal of HighPerformance Business, 1, 1-10. 
Sørensen, F., Sundbo, J., \& Mattsson, J. (2013). Organisational conditions for service encounter-based innovation. Research Policy, 42(8), 1446-1456.

Stanko, M. A., Molina-Castillo, F. J., \& Munuera-Alemán, J. L. (2012). Speed to market for innovative products: blessing or curse? Journal of Product Innovation Management, 29(5), 751-765.

Stone, M. (1974). Cross validatory choice, assessment of statistical predictions. Journal of the Royal Statistical Society. Series B (Methodological), 111-147.

Storey, C. D., \& Easingwood, C. J. (1996). Determinants of new product performance: a study in the financial services sector. International Journal of Service Industry Management, 7(1), 32-55.

Storey, C. D., \& Easingwood, C. J. (1998). The augmented service offering: a conceptualization and study of its impact on new service success. Journal of Product Innovation Management, 15(4), $335-351$.

Storey, C. D., \& Hull, F. M. (2010). Service development success: a contingent approach by knowledge strategy. Journal of Service Management, 21(2), 140-161.

Strambach, S. (2008). Knowledge-intensive business services (KIBS) as drivers of multilevel knowledge dynamics. International Journal of Services, Technology and Management, 10(2), 152-174.

Tai-Shan, H., Chien-Yuan, L., \& Su-Li, C. (2013). Knowledge intensive business services and client innovation. The Service Industries Journal, 33(15-16), 1435-1455.

Tatikonda, M. V., \& Montoya-Weiss, M. M. (2001). Integrating operations and marketing perspectives of product innovation: the influence of organizational process factors and capabilities on development performance. Management Science, 47(1), 151-172.

Tenenhaus, M., Vinzi, V., Chatelin, Y., \& Lauro, C. (2005). PLS path modeling. Computational Statistics and Data Analysis, 48(1), 159-205.

Thakor, M. V., \& Kumar, A. (2000). What is a professional service? A conceptual review and bi-national investigation. Journal of Services Marketing, 14(1), 63-82.

Thorpe, E. R., \& Morgan, R. E. (2007). In pursuit of the ideal approach to successful marketing strategy implementation. European Journal of Marketing, 41(5/6), 659-677.

Umashankar, N., Srinivasan, R., \& Hindman, D. (2011). Developing customer service innovations for service employees: the effects of NSD characteristics on internal innovation magnitude. Journal of Service Research, 14(2), 164-179.

van der Heijden, G. A., Schepers, J. J., Nijssen, E. J., \& Ordanini, A. (2013). Don't just fix it, make it better! Using frontline service employees to improve recovery performance. Journal of the Academy of Marketing Science, 41(5), 515-530.
Vargo, S. L., \& Lusch, R. F. (2004). Evolving to a new dominant logic for marketing. Journal of Marketing, 68, 1-17.

Vargo, S. L., \& Lusch, R. F. (2008). Service-dominant logic: continuing the evolution. Journal of the Academy of Marketing Science, 36, 1-10.

Vernette, E., \& Hamdi-Kidar, L. (2013). Co-creation with consumers: who has the competence, wants to cooperate. International Journal of Market Research, 55(4), 539-561.

Viljamaa, A., Kolehmainen, J., \& Kuusisto, J. (2010). For and against? An exploration of inadvertent influences of policies on KIBS industries in the Finnish policy setting. The Service Industries Journal, 30(1), 71-84.

Weissenberger-Eibl, M., \& Koch, D. J. (2007). Importance of industrial services and service innovations. Journal of Management and Organization, 13(2), 88-101.

Wetzels, M., Odekerken-Schroder, G., \& Van Oppen, C. (2009). Using PLS path modeling for assessing hierarchical construct models: guidelines and empirical illustration. MIS Quarterly, 33(1), 177-195.

Whitehead, J. C., Groothuis, P. A., \& Blomquist, G. C. (1993). Testing for non-response and sample selection bias in contingent valuation: analysis of a combination phone/mail survey. Economics Letters, 41(2), 215-220.

Wilden, R., Gudergan, S. P., Nielsen, B. B., \& Lings, I. (2013). Dynamic capabilities and performance: strategy, structure and environment. Long Range Planning, 46(1-2), 72-96.

Wold, H. (1985). Systems analysis by partial least squares. In P. Nijkamp, H. Leitner, \& Wrigley (Eds.), Measuring the unmeasurable. The Netherlands: NATO ASI Series: Behavioural, Social Sciences. Martinus Nijhoff Publisers.

Ye, J., Marinova, D., \& Singh, J. (2007). Strategic change implementation, performance loss in the front line. Journal of Marketing, 7(4), 156-171.

Ye, J., Marinova, D., \& Singh, J. (2012). Bottom-up learning in marketing frontlines: conceptualization, processes, and consequences. Journal of the Academy of Marketing Science, 40(6), 821-844.

Yee, R. W. Y., Yeung, A. C. L., \& Cheng, T. C. E. (2008). The impact of employee satisfaction on quality and profitability in high-contact service industries. Journal of Operations Management, 26(5), 651-668.

Zeithaml, V. (1987). Defining, relating price, perceived quality and perceived value. Cambridge: Report No. 87-101, Marketing Science Institute.

Zeithaml, V. A., Bitner, M. J., \& Gremler, D. D. (2009). Services marketing: Integrating customer focus across the firm. Boston: McGrawHill/Irwin.

Zhou, K. Z., Li, J. J., Zhou, N., \& Su, C. (2008). Market orientation, job satisfaction, product quality, and firm performance: evidence from China. Strategic Management Journal, 29(9), 985-1000. 